Article

\title{
Epimedium koreanum Nakai Displays Broad Spectrum of Antiviral Activity in Vitro and in Vivo by Inducing Cellular Antiviral State
}

\author{
Won-Kyung Cho ${ }^{1, \dagger}$, Prasanna Weeratunga ${ }^{2, \dagger}$, Byeong-Hoon Lee ${ }^{2}$, Jun-Seol Park ${ }^{2}$, \\ Chul-Joong Kim ${ }^{2}$, Jin Yeul Ma ${ }^{1, *}$ and Jong-Soo Lee ${ }^{2, *}$
}

1 Korean Medicine (KM) Based Herbal Drug Development Group, Korea Institute of Oriental Medicine, Deajeon 305-764, Korea; E-Mail: wkcho@kiom.re.kr (W.-K.C.)

2 College of Veterinary Medicine, Chungnam National University, 220 Gung-Dong, Yuseong-Gu, Daejeon 305-764, Korea; E-Mails: prasannapdn05@gmail.com (P.W.); byeonghoon_2@naver.com (B.-H.L.); pjs123a@naver.com (J.-S.P.); cjkim@cnu.ac.kr (C.J.K.)

$\dagger$ These authors contributed equally to this study.

* Authors to whom correspondence should be addressed; E-Mails: jongsool@cnu.ac.kr (J.-S.L.); jyma@kiom.re.kr(J.Y.M.); Tel.: +82-42-821-6753; Fax: +82-42-821-8903.

Academic Editor: Curt Hagedorn

Received: 2 December 2014 / Accepted: 14 January 2015 / Published: 20 January 2015

\begin{abstract}
Epimedium koreanum Nakai has been extensively used in traditional Korean and Chinese medicine to treat a variety of diseases. Despite the plant's known immune modulatory potential and chemical make-up, scientific information on its antiviral properties and mode of action have not been completely investigated. In this study, the broad antiviral spectrum and mode of action of an aqueous extract from Epimedium koreanum Nakai was evaluated in vitro, and moreover, the protective effect against divergent influenza A subtypes was determined in BALB/c mice. An effective dose of Epimedium koreanum Nakai markedly reduced the replication of Influenza A Virus (PR8), Vesicular Stomatitis Virus (VSV), Herpes Simplex Virus (HSV) and Newcastle Disease Virus (NDV) in RAW264.7 and HEK293T cells. Mechanically, we found that an aqueous extract from Epimedium koreanum Nakai induced the secretion of type I IFN and pro-inflammatory cytokines and the subsequent stimulation of the antiviral state in cells. Among various components present in the extract, quercetin was confirmed to have striking antiviral properties. The oral administration of Epimedium koreanum Nakai exhibited preventive effects on BALB/c mice
\end{abstract}


against lethal doses of highly pathogenic influenza A subtypes (H1N1, H5N2, H7N3 and H9N2). Therefore, an extract of Epimedium koreanum Nakai and its components play roles as immunomodulators in the innate immune response, and may be potential candidates for prophylactic or therapeutic treatments against diverse viruses in animal and humans.

Keywords: Epimedium koreanum Nakai; herbal medicine; quercetin; antiviral effect; anti-influenza Effect

\section{Introduction}

Many viral infections pose a great danger to humans and livestock, often causing deaths and significant economic losses. For instance, influenza spreads around the world in seasonal epidemics, resulting in approximately three to five million yearly cases of severe illness and approximately 250,000 to 500,000 yearly deaths [1]. During the previous century, deadly viruses have caused pandemics worldwide on a number of occasions [2]. Moreover, new and re-emerging infectious viral diseases will pose a rising global health threat, and the risk of spreading these viruses between continents and countries is even larger [3]. HIV/AIDS, Severe Acute Respiratory Syndrome (SARS), and the recent 2009 pandemic H1N1 influenza are only a few of many examples of emerging infectious diseases in the modern world [4].

A number of preventative and therapeutic measures, including biosecurity, vaccination and antiviral drugs, are routinely used to prevent and treat viral diseases. Vaccines form the basis for the prevention of many viral infections, but there are substantial drawbacks [5]. For the influenza virus only, vaccination failures have been widely documented, and in the elderly population, in which most of the mortality occurs, vaccines are only approximately 50\% effective [6]. Moreover, in the eventuality of a pandemic infection with a new strain, antiviral drugs represent the first line of defense [7]. Due to their metabolic properties, viruses are difficult to control, and there are relatively few drugs for the treatment of viral diseases. However, the side effects associated with the central nervous system and the gastrointestinal tract, as well as the rapid emergence of antiviral resistance during therapy, has limited the usefulness of these drugs [8,9]. Therefore, innovative strategies and responses are required to come across the economic and human health risks associated with viral diseases.

Historically, natural herbal medicines have been used by many societies for the treatment of human diseases. Approximately 20,000 plant species used for medicinal purposes are reported by the WHO [10]. In particular, a lot of extracts or substances from medical herbs or plants have been reported to have antiviral effects against infectious viruses [11]. Therefore, extracts or natural products, as pure compounds or standardized plant extracts, provide unlimited opportunities for new antiviral drugs with high efficacy, low toxicity and minor side effects.

Epimedium koreanum Nakai is an evergreen, perennial flowering plant that belongs to Family Berberidaceae, and the aerial parts of the plant have been widely used in traditional Korean and Chinese herbal medicine to treat infertility, impotence, neurasthenia, cardiovascular diseases, amnesia, lumbago, arthritis, various immune-modulatory problems, and also as an aphrodisiac, and anti-rheumatic, for thousands of years [12-14]. Additionally, recent pharmacological studies demonstrate that Epimedium koreanum Nakai contains anti-inflammatory, hypotensive, anti-oxidant and anti-tumor activities [15-18]. 
Importantly, it has been shown that Epimedium koreanum Nakai enhances the immune function [19,20]. However, the antiviral effect of Epimedium koreanum Nakai has not been completely investigated. Moreover, despite having multiple biological properties, available scientific data on Epimedium koreanum Nakai's immune-modulatory potential and responsible molecules have not been reported.

In this study, we have evaluated the antiviral activities of total aqueous extracts from Epimedium koreanum Nakai against a wide array of viruses in vitro and in vivo. Additionally, we have confirmed the immune-modulatory potential that regulates the innate immune response of Epimedium koreanum Nakai. In addition, we tried to identify the active molecules present in the aqueous fraction. Finally, the prophylactic efficacies of Epimedium koreanum Nakai against divergent influenza A subtypes, including $\{$ A/Aquaticbird/Korea/W81/2005(H5N2)\},\{A/PR/8/34(H1N1)\}, \{A/Aquaticbird/Korea/W44/2005(H7 N3) $\}$ and $\{\mathrm{A} /$ Chicken/Korea/116/2004(H9N2) $\}$ were evaluated in a BALB/c murine infection model.

\section{Materials and Methods}

\subsection{Plant Materials and extract Preparation}

A water-soluble herbal extract of Epimedium koreanum Nakai was prepared by the Herbal Medicine Improvement Research Center, Korea Institute of Oriental Medicine, Daejeon, Republic of Korea. Medicinal herb, the dried bark of the plant, was obtained from Yeongcheon Oriental Herbal Market (Yeongcheon, Korea) and verified by Professor Ki Hwan Bae at the College of Pharmacy, Chungnam National University. In detail, $100 \mathrm{~g}$ of the dried bark was placed in $1 \mathrm{~L}$ of distilled water and extracted by heating for $2.5 \mathrm{~h}$ at $105{ }^{\circ} \mathrm{C}$ using a medical heating plate (Gyeongseo Extractor Cosmos-600, Incheon, Korea). After the extraction, Epimedium koreanum Nakai was filtered using a filter paper $(0.45 \mu \mathrm{m})$ (Millex ${ }^{\circledR}$, Darmstadt, Germany) and stored at $4{ }^{\circ} \mathrm{C}$ for $24 \mathrm{~h}$. The extract was then centrifuged at 12,000 rpm for $15 \mathrm{~min}$. The supernatant was collected, and the $\mathrm{pH}$ was adjusted to 7.0. The total aqueous extract was then subjected to membrane syringe filtration $(0.22 \mu \mathrm{m})$ (Millex ${ }^{\circledR}$, Darmstadt, Germany) and lyophilized. The final yield of the water extract of Epimedium koreanum Nakai was adjusted to $0.1 \mathrm{mg} / \mathrm{mL}$ with phosphate buffered saline (PBS) and stored at $4{ }^{\circ} \mathrm{C}$ until administration.

\subsection{Cells and Viruses}

RAW264.7 (ATCC TIB-71), HEK293T (ATCC-11268), MDCK (ATCC CCL-34, NBL-2) and Vero (ATCC CCL-81) cells were grown in DulbeccoCC CCL-81) cells were grow (DMEM, Invitrogen, Carlsbad, CA, USA) supplemented with 10\% fetal bovine serum (FBS) (Gibco, Grand Island, NY, USA) and $1 \%$ antibiotic/antimycotic solution (Gibco, Grand Island, NY, USA) at $37{ }^{\circ}$ Grand Isla 2 concentration of 5\%. Green Fluorescent Protein (GFP)-tagged Influenza A (A/PuertoRico/8/34(H1N1)(PR8-GFP), Newcastle Disease Virus (NDV-GFP) and challenge Influenza viruses $[\{\mathrm{A} /$ Aquaticbird/Korea/W81/2005(H5N2)\}, \{A/PR/8/34(H1N1)\}, \{A/Aquaticbird/Korea/W44 /2005(H7N3)\}, and $\{\mathrm{A} /$ Chicken/Korea/116/2004(H9N2) $\}]$ were propagated in the allantoic fluid of 10-day-old chicken embryos, and Vesicular Stomatitis Virus (VSV-GFP) and Herpes Simplex Virus (HSV) were propagated on confluent Vero cells. The authors received the Green Fluorescence Protein (GFP)-tagged PR8, NDV, VSV and HSV viruses from Dr. Jae U. Jung, Department of Molecular Microbiology and Immunology, University of Southern California, USA. 


\subsection{Determination of Effective Concentration (EC50) of Epimedium koreanum Nakai in Vitro}

RAW264.7 and HEK293T cells were grown in 96-well plates $\left(2.5 \times 10^{4}\right.$ cells/well and $2 \times 10^{4}$ cells/well, respectively) and incubated at $37{ }^{\circ} \mathrm{C}$ in a $5 \% \mathrm{CO}_{2}$ atmosphere. After 12 hours, the medium was replaced with two-fold serially diluted Epimedium koreanum Nakai (50 aL/well). At 12 hour post treatment (hpt), the cells were washed with PBS once and infected using DMEM containing 1\% FBS. RAW264.7 cells were infected with PR8-GFP (MOI = 1.0), VSV-GFP (MOI = 1), NDV-GFP (MOI = 3.0) or HSV-HFP $(\mathrm{MOI}=3.0)$, and HEK293T cells were infected with VSV-GFP (MOI =0.005) or HSV-GFP $(\mathrm{MOI}=2.0)$ viruses. At 2 hour post infection (hpi), the inocula were removed, washed with PBS once and replaced with DMEM containing 10\% FBS. The experiments were performed in triplicate. GFP expression was measured 24 hpi with the Glomax multi-detection system (Promega, WI, USA), according to the manufacturer's instructions. Graphs were developed for the different cell lines infected with individual viruses based on the dilutions and the GFP expression values. The EC50 values were then calculated as the extract concentration yielding 50\% GFP expression.

\subsection{Determination of the Cytotoxic Concentration (CC50) of Epimedium koreanum Nakai in Vitro}

The $\mathrm{CC}_{50}$ was evaluated in a cell viability assay through the trypan blue exclusion test as described elsewhere [21]. The assay was performed using 72-well tissue culture plates. Increasing concentrations $(1-160 \mu \mathrm{L} / \mathrm{mL}$ or $0.1-16 \mu \mathrm{g} / \mathrm{mL}$ ) of the plant extract were added to confluent RAW264.7 and HEK293T cell monolayers. After $24 \mathrm{~h}$, the cell viability was determined by trypan blue exclusion test. Clarified cells from each treatment group were mixed with $0.4 \%$ trypan blue stain (Invitrogen, USA) at a 1:1 ratio. After staining, $10 \mu \mathrm{L}$ of the mixture was applied to a hemocytometer to obtain the percentages of viable cells; the total number of viable/live cells per $\mathrm{mL}$ of aliquot was divided by the total number of cells $/ \mathrm{mL}$ of aliquot multiplied by 100 . Cell counting was done thrice. A graph of the concentrations of the extract as a function of cell viability was developed, and the $\mathrm{CC}_{50}$ was calculated as the concentration of the extract resulting in $50 \%$ cell viability. The experiment was performed in triplicate.

\subsection{Antiviral Assays in Epimedium koreanum-Treated RAW264.7 and HEK293T Cells}

A viral replication inhibition assay was performed according to Moon et al., [22], with some modifications. RAW264.7 cells were grown in 12 -well tissue culture plates $\left(8 \times 10^{5}\right.$ cells/well $)$ and incubated at $37{ }^{\circ} \mathrm{C}$ for $12 \mathrm{~h}$. Simultaneously, HEK293T cells were cultured in six-well tissue culture plates $\left(1 \times 10^{6}\right.$ cells/well) under similar conditions. DMEM alone (untreated and virus-only groups), DMEM with $1000 \mathrm{U}$ of recombinant mouse/human interferon (IFN)- $\beta$ (positive control, Sigma, St. Louis, Missouri, USA) and DMEM with $1.0 \mu \mathrm{g} / \mathrm{mL}(10 \mu \mathrm{L} / \mathrm{mL}$ or $1 \%)$ of Epimedium koreanum Nakai were incubated in different wells for the pre-treatment assay. At $12 \mathrm{~h}$ post-treatment (hpt), all of the wells were gently washed with phosphate-buffered saline (PBS) before infection. RAW264.7 cells were infected with either VSV-GFP (MOI = 1.0), PR8-GFP (MOI = 1.0), NDV-GFP (MOI = 3.0) or HSV-GFP $(\mathrm{MOI}=3.0)$, using DMEM supplemented with 1\% FBS. Additionally, HEK293T cells were infected with VSV-GFP $(\mathrm{MOI}=0.005)$ and HSV-GFP $(\mathrm{MOI}=2.0)$ viruses. Two hours post-infection (hpi), the unattached viruses were aspirated out with the supernatant, and the wells were gently washed with PBS. Then, DMEM supplemented with $10 \%$ FBS and 1\% antibiotic/antimycotic solution was added to 
the wells. GFP expression, which reflects virus replication, was observed at $24 \mathrm{~h}$ post infection (hpi) at $200 \times$ magnification. The virus titration and cell viability were determined at both 12 and 24 hpi. The cell viability was determined via trypan blue exclusion, and the cell counts were performed in triplicate.

\subsection{NDV-GFP mRNA Expression and Virus Titration in RAW 264.7 Cells}

The total mRNA from RAW264.7 cells was extracted and amplified to estimate the NDV-GFP mRNA expression level [23]. RAW264.7 cells were cultured in 12-well tissue culture plates $\left(8 \times 10^{5}\right.$ cells/well) and incubated for $12 \mathrm{~h}$. The medium was replaced with DMEM alone (untreated and virus-only groups) or DMEM with $1.0 \mu \mathrm{g} / \mathrm{mL}(10 \mu \mathrm{L} / \mathrm{mL}$ or $1 \%)$ Epimedium koreanum Nakai. Twelve hours post-treatment, the cells were infected with NDV-GFP $(\mathrm{MOI}=3)$ and harvested at $0,6,12$, and 24 hpi. The total mRNA was extracted using the RNeasy Mini Kit (Qiagen, Seoul, Korea) and then converted to cDNA, and PCR was then performed using specific primers. For the APMV-1 M gene, the forward primer was 5'- -TCGAGICTGTACAATCTTGC-3 and the reverse primer was 5'- GTCCGAGCACATCACT GAGC-3'. For the GAPDH, the forward primer was 5'-TGACCACAG TCCATGCCATC-3' and the reverse primer was 5'-GACGGACACATTGGG GGTAG-3' [24]. Equal amounts of the PCR products were run on 1.5\% ethidium bromide agarose gels and visualized using a GelDoc Imaging System (Bio-Rad, Seoul, Korea). Finally, the relative band intensity (RBI) of the matrix gene compared with that of GAPDH was determined using the GelDoc Imaging System Band Quantification Software (Bio-Rad).

\subsection{Virus Titration of Treated Cell Supernatants and Infected Cells}

The viral titers were measured by plaque assays using Vero cells [25]. Briefly, RAW264.7 and HEK293T cells were cultured in six-well tissue culture plates $\left(1 \times 10^{6}\right.$ cells/well and $8 \times 10^{5}$ cells/well, respectively) and incubated for $12 \mathrm{~h}$. The medium was replaced with DMEM alone (untreated and virus-only groups), DMEM with $1000 \mathrm{U}$ of recombinant mouse/human interferon (IFN)-MEM alone with $1.0 \mu \mathrm{g} / \mathrm{mL}$ (10 $\mu \mathrm{L} / \mathrm{mL}$ or 1\%) Epimedium koreanum Nakai. Twelve hours post-treatment, RAW264.7 cells were infected with PR8-GFP (MOI $=1.0)$, VSV-GFP (MOI $=1.0)$, NDV-GFP $(\mathrm{MOI}=3.0)$ or HSV-GFP $(\mathrm{MOI}=3.0)$, and HEK293T cells were infected with VSV-GFP $(\mathrm{MOI}=0.005)$ and HSV-GFP $(\mathrm{MOI}=2.0)$ viruses. For the titration of VSV-GFP, supernatants from each group were collected at 12 and 24 hpi and serially diluted. Independently, VERO cells were cultured in 12-well plates, and when the cell confluency was approximately $75 \%-80 \%$, the cells were infected with $500 \mu \mathrm{L}$ of each dilution. Following $2 \mathrm{~h}$ incubation at $37^{\circ} \mathrm{C}$, the inoculum was removed and replaced with agar $(0.45 \mathrm{~g} / 20 \mathrm{ml} \mathrm{DW})$. The plates were then incubated for another $46 \mathrm{~h}$ at $37^{\circ} \mathrm{C}$ and examined for plaque formation at 200x magnification. The viral titers were calculated using the number of plaque-forming units and the dilution factor. In the case of PR8-GFP and HSV-GFP titration, instead of the cell supernatant, infected cells from each group were harvested at 12 and $24 \mathrm{hpi}$ and subjected to five cycles of freezing at $-70{ }^{\circ} \mathrm{C}$ and thawing at room temperature. The cells were then re-suspended with $500 \mu \mathrm{L}$ of phosphate-buffered saline (PBS) and serially diluted before being used to infect Vero cells. 


\subsection{Detection of IFN- $\beta$ and Pro-Inflammatory Cytokines in Epimedium koreanum Nakai-Treated RAW264.7 and HEK293T Cells by Enzyme-Linked Immunosorbent Assay (ELISA)}

The pro-inflammatory cytokine inducing effect of Epimedium koreanum Nakai in vitro was examined using commercial ELISA kits. In the case of RAW264.7 cells, murine interleukin (IL)-6 (BD Bioscience, USA), and IFN- $\beta$ (PBL Interferon Source, USA) were measured, as previously described [26]. Briefly, RAW264.7 cells were cultured in 6-well tissue culture (TC) plates $\left(1 \times 10^{6}\right.$ cells/well $)$. After $12 \mathrm{~h}$, the cells were treated with 1000 units $/ \mathrm{mL}$ recombinant murine IFN- $\beta$ (Sigma-Aldrich) and $1.0 \mu \mathrm{g} / \mathrm{mL}$ $(10 \mu \mathrm{l} / \mathrm{mL}$ or $1 \% \mathrm{v} / \mathrm{v})$ Epimedium koreanum Nakai in DMEM containing $10 \%$ FBS or medium alone and then incubated at $37{ }^{\circ} \mathrm{C}$ with $5 \% \mathrm{CO}_{2}$. Supernatants were harvested at 0,12 and $24 \mathrm{hpt}$, clarified by centrifugation at $2500 \times \mathrm{g}$ for $10 \mathrm{~min}$ at $4{ }^{\circ} \mathrm{C}$ and dispensed into murine IFN- $\beta$ ELISA plates or murine IL- 6 capture antibody-coated ELISA plates. In the case of HEK293T cells (cell count: $\left(1 \times 10^{6}\right.$ cells/well), recombinant human IFN- $\beta$ (Sigma-Aldrich) was used as the positive control and the clarified supernatant was dispensed into commercial human IFN- $\beta$ (TFB, Inc., Tokyo, Japan) and human IL-6 (Invitrogen, Carlsbad, California, USA) ELISA plates. Murine IFN- $\beta$, human IFN- $\beta$ and human IL-6 ELISA were performed in duplicate, and murine IL-6 ELISA was performed in triplicate.

\subsection{Determination of the Level of $m R N A$ Induction by Epimedium koreanum Nakai in Vitro by Real-Time PCR Analysis}

RAW264.7 and HEK293T cells were grown in six-well tissue culture (TC) plates $\left(1 \times 10^{6}\right.$ cells/well $)$ and incubated at $37^{\circ} \mathrm{C}$; the cells were treated with DMEM $+10 \% \mathrm{FBS}$ alone (negative control), DMEM with 1000 units/mL recombinant murine/human IFN- $\beta)$, DMEM with $1.0 \mu \mathrm{g} / \mathrm{mL}(10 \mu \mathrm{l} / \mathrm{mL}$ or $1 \%)$ Epimedium koreanum Nakai, and the cells were harvested at 0, 3, 6, 12, and 24 hpt. The total RNA from the cells was isolated using the RNeasy Mini Kit (Qiagen, Seoul, Korea), and cDNA synthesis was performed using reverse transcriptase (Toyobo, Japan). The different levels of cDNA were quantified by real-time polymerase chain reaction (PCR) using a QuantiTect SYBR Green PCR kit (Qiagen, Seoul, Korea) on a Mygenie96 thermal block (Bioneer, Korea). The PCR primers are listed in Tables 2 and 3.

\subsection{Immunoblot Analysis to Determine the Effect of Epimedium koreanum Nakai on Type I IFN-Related Protein Phosphorylation in RAW264.7 Cells}

RAW264.7 cells were cultured in six-well tissue culture $(\mathrm{TC})$ plates $\left(1 \times 10^{6}\right.$ cells/well $)$ and incubated at $37^{\circ} \mathrm{C}$. After 12 hours the cells were treated with DMEM $+10 \%$ FBS alone (negative control), DMEM with $100 \mathrm{ng} / \mathrm{mL}$ LPS (positive control), or DMEM with $1.0 \mu 0 / \mathrm{mL}(10 \mu \mathrm{L} / \mathrm{ml}$ or $1 \%$ ) Epimedium koreanum Nakai, and the cells were harvested at $0,8,12$, and $24 \mathrm{hpt}$. The cell pellets were washed with phosphate-buffered saline (PBS) and subjected to immunoblot analysis. Briefly, the cell pellets were lysed in radio-immunoprecipitation assay (RIPA) lysis buffer (50 mM Tris- $\mathrm{HCl}$ (pH 8.0), $150 \mathrm{mM} \mathrm{NaCl}$, $0.5 \%$ sodium deoxycholate, $1 \%$ IGEPAL, $1 \mathrm{mM} \mathrm{NaF}, 1 \mathrm{mM} \mathrm{Na}$ VO 4 , and $1 \mathrm{ug} / \mathrm{mL}$ each of aprotinin and leupeptin). The samples were separated by SDS-PAGE and transferred onto a PVDF membrane (BioRad) in buffer containing $30 \mathrm{mM}$ Tris, $200 \mathrm{mM}$ glycine, and 20\% methanol for $2 \mathrm{~h}$. The membranes were blocked for $1 \mathrm{~h}$ in Tris-buffered saline containing 0.05\% Tween 20 and 5\% bovine serum albumin and were then probed with the target protein antibody in 5\% FBS-TBST. These incubations were 
performed at $4{ }^{\circ} \mathrm{C}$ overnight with anti-IRF3 (Abcam, \#ab25950), anti-phopho-IRF3 (Ser 396), (Cell Signaling, \#4947), anti-p65 (Cell Signaling, \#4764S), anti-phopho-p65 (Cell Signaling, \#3031S), antiSTAT1 (Cell Signaling, \#9175), anti-phospho-STAT1 (Cell Signaling, \#9167), anti-TBK1 (Cell Signaling, \#3504S), or anti-phospho-TBK1 (Cell Signaling, \#5483S), anti-p38 (Cell Signaling, \#9212), anti-phopho-p38 (Cell Signaling \#4631S), anti-ERK (Cell Signaling, \#9102), anti-phospho-ERK (Cell Signaling, \#9102S), or anti-B-actin (Santa Cruz SC 47778) antibodies. After three 10-min washes with Tris-buffered saline containing $0.05 \%$ Tween 20 , the membranes were incubated with a horseradish peroxidase-conjugated secondary antibody for 1 hour at room temperature. After three 10-min washes with PBST, the HRP reaction was visualized with the enhanced chemiluminescence detection system (ECL-GE Healthcare) using a Las-3000 mini Lumino Image Analyzer.

\subsection{Oral Inoculation of Epimedium koreanum Nakai and Viral Challenge in BALB/c Mice}

Fifty-two female, five-week-old BALB/c mice were divided into four experimental sets, with two groups per set. Of the four sets, one had two groups with 11 mice each (six for lung virus titration at 3 and 5 days post-infection (dpi)). The remaining three sets had two groups containing five mice each. The mice were orally administered $0.1 \mathrm{mg} / \mathrm{mL}$ Epimedium koreanum Nakai at a total volume of $200 \mu \mathrm{L}$ (20 $\mu \mathrm{g}$ per head) 1, 3 and 5 days before infection. The mice in the control groups were orally administered $200 \mu \mathrm{L}$ of PBS.

The mice were intra-nasally infected with five times the $50 \%$ mouse lethal dose (MLD 50 ) of H1N1, H5N2, H7N3 or H9N2 in $20 \mu \mathrm{l}$ of PBS per mouse. Treatment and challenge experiments were conducted in an approved BSL-2 + facility. The body weight and survival were recorded up to 13 dpi. Mice showing a more than $25 \%$ body weight loss were considered to have reached the experimental end point and were humanely killed. At 3 and 5 dpi, three mice from each of the two groups from the H1N1-challenged set were randomly sacrificed to measure the lung virus titers.

The animal study was conducted under appropriate conditions with the approval of the Institutional Animal Care and Use Committee of the Bioleaders Corporation, Daejeon, South Korea, Protocol number: BSL-ABLS-13-004. They are in accordance with Institutional, National and International laws for Laboratory Animal Experimentation.

\subsection{Determination of Lung Viral Titer}

Lung tissues from euthanized mice were collected aseptically, and virus titers were determined by $50 \%$ tissue culture infectious dose (TCID 50 ), as described previously [27]. Briefly, lung tissues were homogenized in $500 \mathrm{~mL}$ of PBS containing antibiotics (penicillin, and streptomycin) and antimycotics (Fungizone) compounds (Gibco, Grand Island, NY, USA). Mechanically homogenized lung samples were centrifuged $\left(15 \mathrm{~min}, 12,000 \times \mathrm{g}\right.$ and $\left.4{ }^{\circ} \mathrm{C}\right)$ to remove the cellular debris before their storage at $-80{ }^{\circ} \mathrm{C}$. Madin-Darby Canine Kidney (MDCK) cells ( $75 \%-80 \%$ confluent) grown in 96 -well microtiter plates were infected with 10-fold serial dilutions (in DMEM containing 1\% FBS) of lung homogenate (50 $\mu \mathrm{L} /$ well) in quadruplicate and incubated at $37{ }^{\circ} \mathrm{C}$ in a humid atmosphere of $5 \% \mathrm{CO}_{2}$ for an hour. After absorption, the media was removed, and overlay medium containing L-1-tosylamido-2-phenylethyl chloromethyl ketone (TPCK) trypsin (Thermo Fisher Scientific, Rockford, USA) was added to the infected cells and incubated for $72 \mathrm{~h}$. Viral cytopathic effects (CPE) were observed daily, and the titers 
were determined by the hemagglutination assay (HA) test indicated as follows. Fifty microliter $(50 \mu \mathrm{L})$ of $0.5 \%$ chicken red blood cells (RBC) was added to $50 \mu \mathrm{L}$ of cell culture supernatant and incubated at room temperature for $30 \mathrm{~min}$. Wells containing HA were scored as positive. The virus titer was calculated by the Reed and Muench method [28] and expressed as $\log _{10}$ TCID50/mL of lung tissues.

\subsection{Anti-Influenza Effect and Induction of Cytokines by Quercetin on RAW264.7 Cells}

Quercetin was kindly provided by Dr. Jin Yeul Ma, Herbal Medicine Improvement Research Center, Korea Institute of Oriental Medicine, Daejeon, Republic of Korea. The main component profile of the water extract of Epimedium koreanum Nakai had been analyzed using high-performance liquid chromatography (HPLC) and quercetin had been successfully purified (14). Then, we tested the anti-influenza (PR8-GFP) effect of quercetin upon pre-treatment of the compound. Quercetin was treated at a concentration of $3.0 \mu \mathrm{g} / \mathrm{mL}, 12 \mathrm{~h}$ before infection with PR8-GFP (MOI $=1.0)$ and GFP expression was observed at $24 \mathrm{~h}$ post infection (hpi) at $200 \times$ magnification. Mouse interferon (IFN)- $\beta$ was treated as the positive control (1000 units/mL). Further, virus titration, secretion of cytokines (IL- 6 , TNF- $\alpha$ and IFN- $\beta$ ) by quercetin $(3.0 \mu \mathrm{g} / \mathrm{mL})$ in RAW264.7 cells were determined by the methods described in 3.7 and 3.8.

\subsection{Statistical Analysis}

Data are presented as the means \pm standard deviations and are representative of at least three independent experiments. Differences between groups were analyzed by analysis of variance (ANOVA), and means were compared by Student's $t$-test. $p$-values less than 0.05 were regarded as significant. Results for percent initial body weight were also compared by using Student's $t$ test. Comparison of survival was done by log-rank test using GraphPad Prism 6 version.

\subsection{Biodiversity Rights}

Authors have not violated any biodiversity rights during the handling and preparation of Epimedium koreanum Nakai and throughout the entire experimental period.

\section{Results and Discussion}

\subsection{Determination of the Effective Concentration (EC50) and Cytotoxic Concentration (CC50) of} Epimedium koreanum Nakai in Vitro

The $\mathrm{EC}_{50}$ can be defined as the extract concentration at which $50 \%$ reduction in virus titre is observed, whereas the extract concentration that results in $50 \%$ cell viability is considered the $\mathrm{CC}_{50}$. To determine the EC50 values of Epimedium koreanum Nakai against divergent viruses in vitro, we developed a modified GFP assay using RAW264.7 and HEK293T cell lines [29,30]. For the reason that, we used only the GFP-tagged viruses, $50 \%$ reduction in GFP expression was considered equivalent to the $50 \%$ reduction in virus titre.

As shown in Table 1, Epimedium koreanum Nakai can inhibit the replication of PR8-GFP (MOI = 1.0), VSV-GFP $(\mathrm{MOI}=1.0)$, NDV-GFP $(\mathrm{MOI}=3.0)$ and HSV-GFP $(\mathrm{MOI}=3.0)$ by $50 \%$ at EC50 values of 
$0.94 \pm 0.23 \mu \mathrm{g} / \mathrm{mL}, 0.82 \pm 0.28 \mu \mathrm{g} / \mathrm{mL}, 0.49 \pm 0.25 \mu \mathrm{g} / \mathrm{mL}$ and $0.62 \pm 0.14 \mu \mathrm{g} / \mathrm{mL}$, respectively. Moreover, extracts inhibited the replication of VSV-GFP (MOI =0.005) and HSV-GFP $(\mathrm{MOI}=2.0)$ by $50 \%$ at $\mathrm{EC}_{50}$ values of $1.12 \pm 0.31 \mu \mathrm{g} / \mathrm{mL}$ and $1.41 \pm 0.41 \mu \mathrm{g} / \mathrm{mL}$ in HEK293T cells (Table 1). Considering these EC50 values, we selected $1.0 \mu \mathrm{g} / \mathrm{mL}$ as the optimum dosage of the extract for further in vitro antiviral assays based on its effectiveness and convenience during the experiments.

Table 1. Determination of $\mathrm{EC}_{50}$ and $\mathrm{CC}_{50}$ of Epimedium koreanum Nakai in RAW264.7 and HEK293T cells.

\begin{tabular}{|c|c|c|c|c|c|}
\hline \multirow{2}{*}{ Cell line } & \multicolumn{4}{|c|}{$\mathrm{EC}_{50} \pm$ S.D. $^{\mathrm{a}}(\mu \mathrm{g} / \mathrm{mL})$} & \multirow{2}{*}{$\mathrm{CC}_{50} \pm$ S.D. $^{\mathrm{b}}(\mu \mathrm{g} / \mathrm{mL})$} \\
\hline & PR8-GFP & VSV-GFP & NDV-GFP & HSV-GFP & \\
\hline Raw264.7 & $0.94 \pm 0.23$ & $0.82 \pm 0.28$ & $0.49 \pm 0.25$ & $0.62 \pm 0.14$ & $14.6 \pm 1.68$ \\
\hline HEK293T & - & $1.12 \pm 0.31$ & - & $1.41 \pm 0.41$ & $8.4 \pm 1.96$ \\
\hline
\end{tabular}

${ }^{a}$ Effective concentration for $50 \%$ reduction in GFP expression. ${ }^{\mathrm{b}}$ Cytotoxic concentration causing $50 \%$ cell death. The results are a mean of three independent experiments.

The cytotoxicity of Epimedium koreanum Nakai was assessed based on a cell viability test following treatment with various concentrations. Epimedium koreanum Nakai had $\mathrm{CC}_{50}$ values of $14.6 \pm 1.68 \mu \mathrm{g} / \mathrm{mL}$ and $8.4 \pm 1.96 \mu \mathrm{g} / \mathrm{mL}$ in RAW264.7 and HEK293T cells, respectively (Table 1). The selection indexes of Epimedium koreanum Nakai (SI) for PR8, VSV, NDV and HSV on RAW264.7 cells were 15.5, 17.8, 29.8 and 23.5, respectively and for VSV and HSV on HEK293T cells were 7.5 and 5.9, respectively, suggesting that the extract could be broadly useful as a prophylactic or therapeutic agent.

\subsection{Inhibitory Effects of Epimedium koreanum Nakai on Viruses in RAW264.7 Cells}

To evaluate the in vitro antiviral activity of Epimedium koreanum Nakai, we checked viral replication with divergent GFP-expressing viruses, including RNA and DNA viruses, in RAW264.7 cells. Viral replication was monitored with GFP-expressing level upon treatment with cytotoxic-free (data not shown) extracts. A total aqueous extract of Epimedium koreanum Nakai-treated RAW264.7 cells $(1 \mu \mathrm{g} / \mathrm{mL}(1 \% \mathrm{v} / \mathrm{v}))$ exhibited a marked reduction in GFP expression, whereas the untreated groups had high levels of GFP expression for VSV (Figure 1A), PR8 (Figure 1B), NDV (Figure 1C) and HSV (Figure 1D). When quantitated, extract-treated cells showed a significant reduction in GFP expression compared to the untreated group (data not shown). These results correlate with the viral titers of VSV-GFP in the cell supernatant and the viral titers of PR8-GFP and HSV-GFP in infected cells. Epimedium koreanum Nakai treatment reduced the viral titers by nearly 1.5-fold, 1.8-fold and 2-fold against VSV-GFP, PR8-GFP and HSV-GFP at 24 hpi, respectively (Figure 1A-C). Importantly, Epimedium koreanum Nakai-treated cells displayed a significant reduction in cell death following infection with all tested viruses compared with the untreated cells (Figure 1A-D). In the case of NDV, we measured the mRNA expression of the NDV M gene via RT-PCR to estimate the replication (Figure $1 \mathrm{C}$ right panels) of NDV-GFP. As expected, the expression of the Matrix gene mRNA in the extracttreated cells was decreased in a time-dependent manner compared with the untreated group at 6-24 hpi. 
These results clearly show evidence that the total aqueous extract of Epimedium koreanum Nakai is able to reduce the replication of the VSV, PR8, NDV and HSV viruses in RAW264.7 cells.

\subsection{Inhibitory Effects of Epimedium koreanum Nakai on Viruses in HEK293T Cells}

We then determined the antiviral activity of Epimedium koreanum Nakai in Human Embryonic Kidney (HEK293T) cells. Similarly; anti-viral activity was observed with GFP-tagged VSV and HSV viruses upon pre-treatment with the extract. As shown in Figure 2A,B; extract-treated HEK293T cells exhibited markedly reduced GFP expression and virus titers compared with the untreated groups; which presented high levels of GFP expression and virus replication. Moreover, extract-treated HEK293T cells showed a significant reduction in cell death following infection with all tested viruses compared with the untreated cells. These results clearly indicate that the total aqueous extract of Epimedium koreanum Nakai also reduce the replication of RNA or DNA viruses in epithelial cells.

A

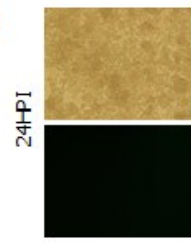

Medium

B

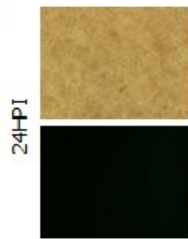

Medium

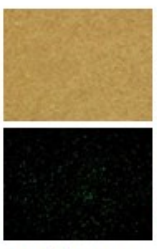

IFN- $\beta$ /PR8-GFP

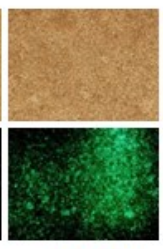

PR8-GFP

C

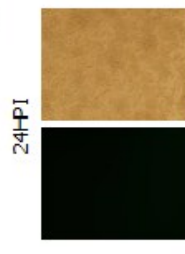

Medium

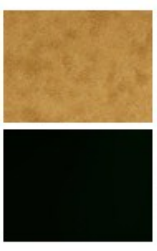

IFN- $\beta /$ NDV-GFP

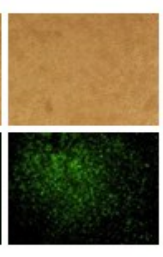

NDV-GFP

D

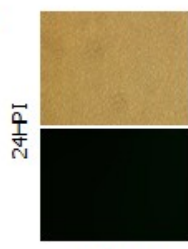

Medium

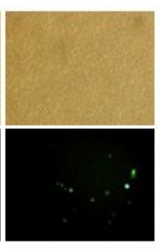

IFN- $\beta$ /HSV-GFP

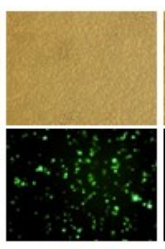

HSV-GFP

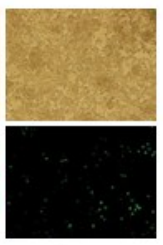

EKN/VSV-GFP
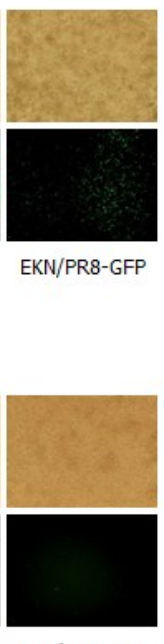

EKN/NDV-GFP

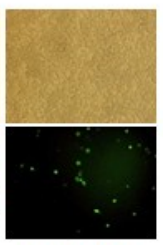

EKN/HSV-GFP
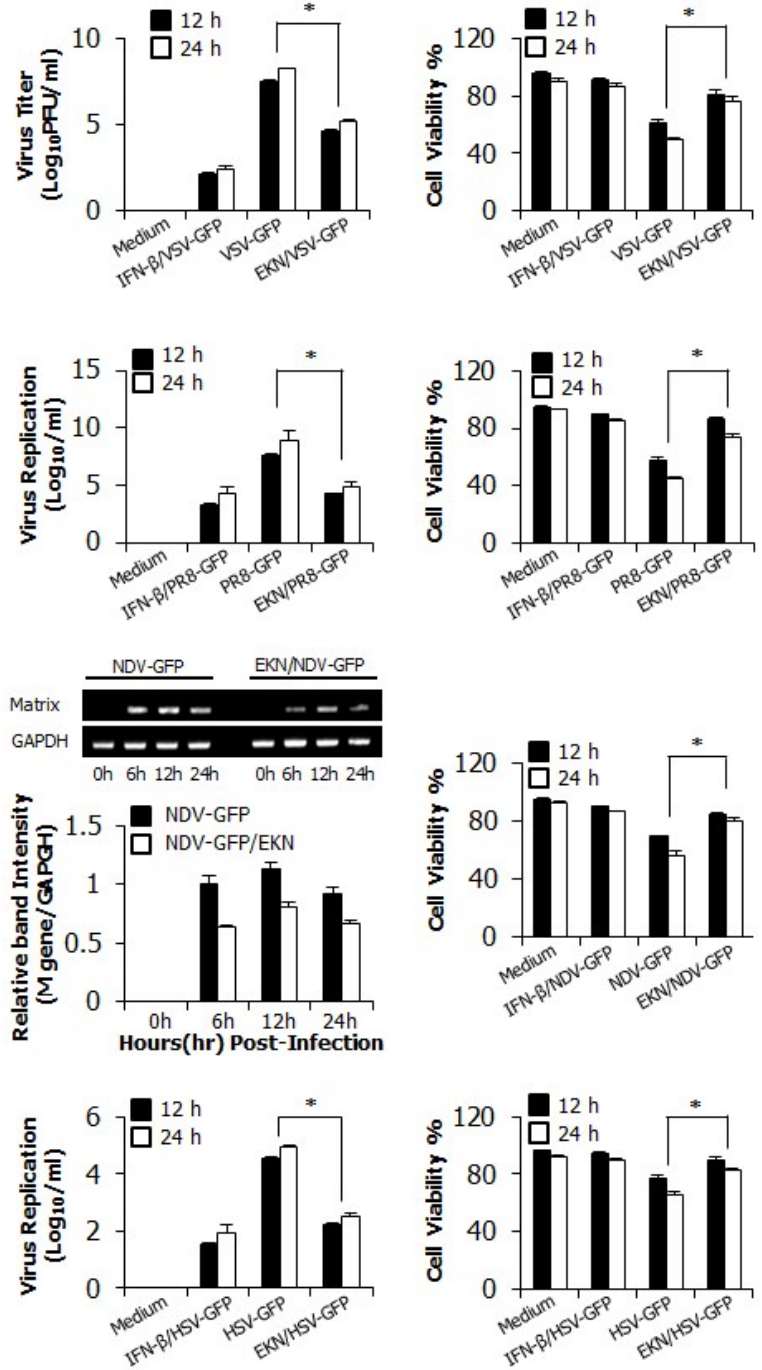

Figure 1. Antiviral activities of Epimedium koreanum Nakai in RAW264.7 cells. RAW264.7 cells treated with media alone, $1.0 \mu \mathrm{g} / \mathrm{mL}$ Epimedium koreanum Nakai (EKN), or 1000 unit/mL recombinant mouse IFN- $\beta, 12 \mathrm{~h}$ prior to infection with (A) VSV-GFP; or (B) PR8-GFP; or (C) NDV-GFP; or (D) HSV-GFP at an MOI of 1.0. Images were 
obtained 24 hpi $(200 \times$ magnification). Cell viabilities were determined by trypan blue exclusion and presented as a percentage of the control (cells without treatment). Viruses were titrated from the supernatant for VSV-GFP and from the infected cells for PR8-GFP and HSV-GFP, respectively. In the case of NDV-GFP, expression of NDV M-mRNA over time in each treatment group was confirmed by specific PCR primers, which are shown in Table 2. All samples were normalized using GAPDH. Equal amounts of PCR products were run on $1.5 \%$ ethidium bromide agarose gels and visualized using the GelDoc Imaging System (bottom panel). The relative band intensity (RBI) of M-mRNA expression from the same experiment is shown (top panel). RBI was determined (gene/GAPDH) using the GelDoc Imaging System Band Quantification Software. Error bars indicate the range of values obtained from two independent experiments. Cell viabilities are expressed as mean \pm SD. Error bars indicate the range of values obtained from counting in triplicate in three independent experiments. (* $p<0.05$ indicates a significant difference between groups compared by Student's $t$-test).

A

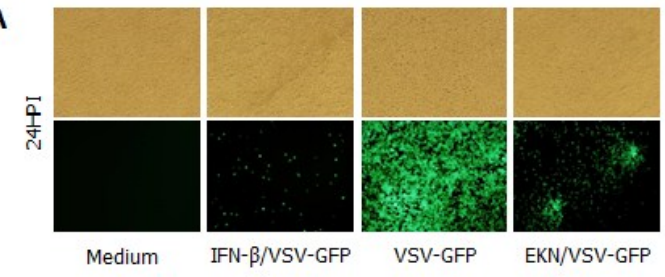

B

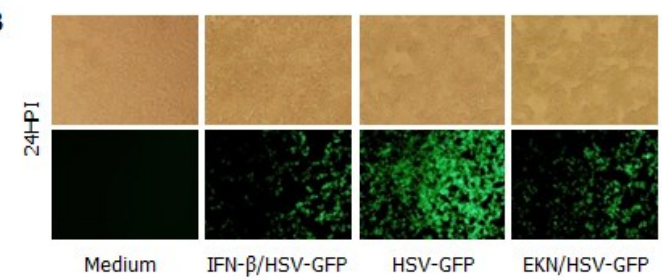

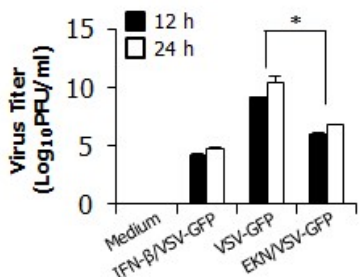
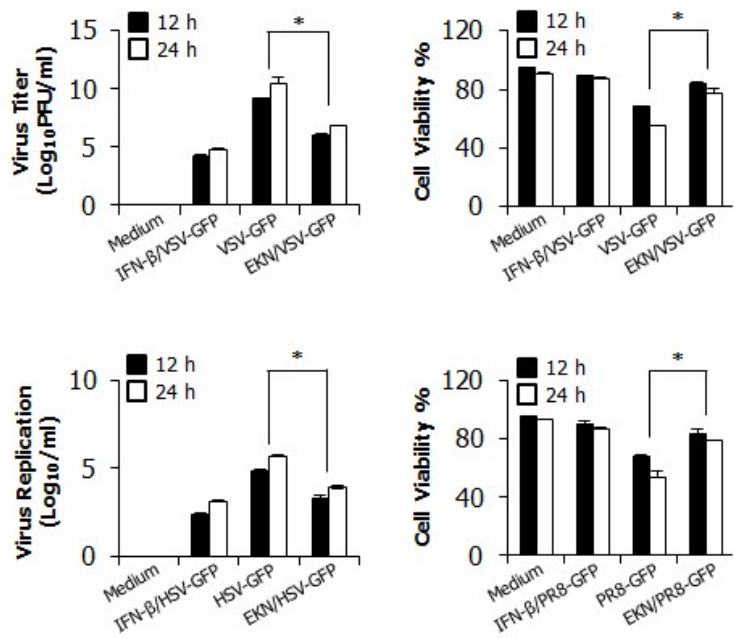

Figure 2. Antiviral activities of Epimedium koreanum Nakai in HEK293T cells. HEK293T cells treated with media alone, $1.0 \mu \mathrm{g} / \mathrm{mL}$ Epimedium koreanum Nakai (EKN), or $1000 \mathrm{unit} / \mathrm{mL}$ recombinant human IFN- $\beta, 12 \mathrm{~h}$ prior to infection with (A) VSV-GFP; or (B) HSV-GFP at an MOI of 1.0 and 3.0, respectively. Images were obtained at $24 \mathrm{hpi}(200 \times$ magnification $)$. Viruses were titrated from the cultured supernatant and from the infected cells for VSV-GFP and HSV-GFP, respectively. Virus titrations are expressed as mean \pm SD. Error bars indicate the range of values obtained from two independent experiments. Cell viabilities were determined by trypan blue exclusion and presented as a percentage of the control (cells without treatment). Cell viabilities are expressed as mean $\pm \mathrm{SD}$. Error bars indicate the range of values obtained from counting in triplicate in three independent experiments ${ }^{*} p<0.05$ indicates a significant difference between groups compared by Student's $t$-test).

\subsection{Detection of IFN- $\beta$ and Pro-Inflammatory Cytokines by Epimedium koreanum Nakai in Vitro}

To elucidate the possible mechanism of the antiviral activities of Epimedium koreanum Nakai, we measured the levels of interferon- $\beta$ (IFN- $\beta$ ) and the pro-inflammatory cytokine that is secreted from 
the extract-treated supernatant, on RAW264.7 and HEK293T cells (Figure 3). As shown in Figure 3A, Epimedium koreanum Nakai induced high levels of secreted IL-6 at both $12 \mathrm{hpt}$ and $24 \mathrm{hpt}$ compared with IFN- $\beta$-treated cells in a concentration-dependent manner and also secreted significantly higher levels of IFN- $\beta$, although the secreted level was not as high as the levels obtained from the IFN- $\beta$-treated cells. Moreover, Epimedium koreanum Nakai induced the secretion of IFN- $\beta$ and IL-6 in HEK293T cells (Figure 3B) and the secreted amount was significantly high, and in line with human IFN- $\beta$-treated positive controls. These results suggest that Epimedium koreanum Nakai can stimulate immune cells and epithelial cells and induce the secretion of IFNs and pro-inflammatory cytokines that may mediate the antiviral state in cells.
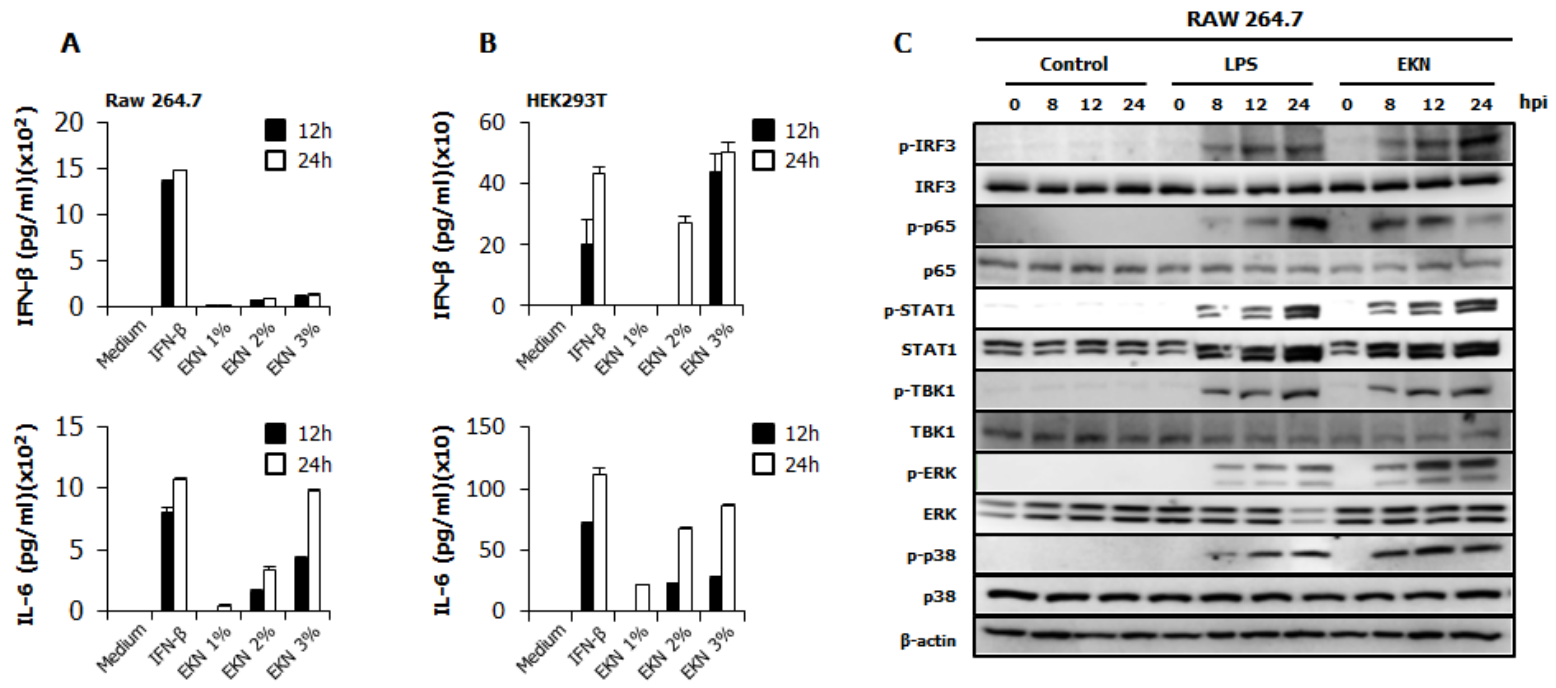

Figure 3. Induction of cytokines and the phosphorylation of the signal molecules by Epimedium koreanum Nakai in vitro. (A) RAW264.7; and (B) HEK293T cells were treated with DMEM containing 10\% FBS alone, with 1000 unit $/ \mathrm{mL}$ recombinant mouse or human IFN- $\beta$, or with $1.0 \mu \mathrm{g} / \mathrm{mL}$ Epimedium koreanum Nakai (EKN) and incubated at $37{ }^{\circ} \mathrm{C}$ with $5 \% \mathrm{CO}_{2}$. Supernatant from each group was harvested at 0,12 and $24 \mathrm{hpt}$ and clarified by centrifugation at $2500 \times \mathrm{g}$ for $10 \mathrm{~min}$ at $4{ }^{\circ} \mathrm{C}$. Clarified supernatants were dispensed into the murine IFN- $\beta$ and IL-6, and human IL- 6 and IFN- $\beta$ capture antibody-coated ELISA plate to measure cytokine secretion. The test was performed in duplicate for IFN- $\beta$, human IL-6 and in triplicate for other cytokines. The data shows representative means \pm SD of each murine cytokine measured over time. (C) For the determination of Type I IFN-related or $\mathrm{NF}-\kappa \mathrm{B}$ related protein phosphorylation, cells were harvested at $0,8,12$, and $24 \mathrm{hpt}$ with LPS or Epimedium koreanum Nakai (EKN) and washed with phosphate-buffered saline (PBS) and subjected to immunoblot analysis. The samples were separated by SDS-PAGE, transferred onto a PVDF membranes and were probed with the target protein antibodies (anti-IRF3/anti-phopho-IRF3, anti-p65/anti-phopho-p65, anti-STAT1/anti-phopho-STAT1, anti-TBK1/anti-phopho-TBK1, anti-p38/anti-phopho-p38, anti-ERK/anti-phopho-ERK, anti- $\beta$-actin) before visualizing with the enhanced chemiluminescence detection system (ECL-GE healthcare) using a Las-3000 mini lumino-image analyzer. 


\subsection{Epimedium koreanum Nakai Induces the Activation of Signal Molecules in the Type I IFN} Signaling Pathway

The antiviral response of Epimedium koreanum Nakai may relate to the innate immune response through the expression of cytokines, such as IL- 6 and IFN- $\beta$. To correlate these observations with the IFN-inducing signaling pathway, we examined the phosphorylation of interferon related signal molecules and p65 phosphorylation related to NF-kB activation. For this, immunoblot analyses were performed using whole cell lysates of extract-treated RAW264.7 cells. As shown in Figure 3C, Epimedium koreanum Nakai significantly upregulated the phosphorylation of IRF-3, STAT1, TBK1, p65, p38 and ERK, which are key signaling molecules belonging to the type I interferons (IFNs) and NF- $\kappa B$ pathways. The phosphorylation of IRF3 is a key indicator of interferon signal transduction. Upon virus infection, the phosphorylated IRF3 translocated into the nucleus and initiated the transcription of type I interferons (IFNs). Consequently, the produced type I interferons (IFNs) binds to the JAK-STAT pathway, leading to the phosphorylation of STAT1 and the transcriptional activation of Interferon-stimulated gene (ISGs). These activated ISGs are then involved in controlling viral infection. Our results clearly demonstrate that treatment with the Epimedium koreanum Nakai extract can induce potent IRF3 phosphorylation at $8 \mathrm{hpt}$, the effect of which markedly increases with time. Furthermore, this increased STAT1 phosphorylation indicates the active functions of the ISGs. In addition to the activation of type I interferons (IFNs), the extract-treated RAW264.7 cells were able to elicit obvious activation of NF- $\mathrm{B}$ (P65), leading to strong secretion of pro-inflammatory cytokines. The phosphorylation of these molecules induced by extracts is comparable to that obtained with LPS treatment, which is a known potent stimulator of TLR4.

\subsection{Epimedium koreanum Nakai Induces Antiviral Gene Expression in the Type I IFN} Signaling Pathway

We further evaluated the induction of different antiviral and interferon-stimulatory genes at the transcription level in response to Epimedium koreanum Nakai treatment in RAW264.7 and HEK293T cells. Cells were treated with Epimedium koreanum Nakai at a concentration of $1.0 \mu \mathrm{g} / \mathrm{mL}(10 \mu \mathrm{L} / \mathrm{mL}$ or $1 \%$ ). As confirmed by real-time PCR, the mRNA expression levels of various antiviral and interferon stimulatory genes were up-regulated to levels similar to those found with the IFN- $\beta$-treated positive controls (Figure 4). Initially, to determine the transcription levels of various antiviral genes in Epimedium koreanum Nakai-treated RAW264.7 cells from $0 \mathrm{hpt}$ to $24 \mathrm{hpt}$, an IFN- $\beta$ real-time PCR assay was performed to monitor the time-dependent mRNA changes. After normalization to GAPDH, the extracttreated cells displayed a seven-fold increase in the level of IFN- $\beta$ mRNA at $8 \mathrm{hpt}$ and a nine-fold induction level at $12 \mathrm{hpt}$ compared with untreated cells, respectively (Figure 4A).

Therefore, we performed a PCR assay for other genes of interest at 0,8 and $12 \mathrm{hpt}$ using specific primers (Tables 2 and 3) in both RAW264.7 and HEK293T cells. We found that the transcriptional levels of various antiviral genes were up-regulated by Epimedium koreanum Nakai at $12 \mathrm{hpt}$, including Mx1, GBP-1 and PML to levels that were 5.6-fold, 28-fold and 15-fold higher, respectively, than those of the control in RAW264.7 cells. Moreover, at 8hpt, the IL-6 and OAS-16 transcriptional levels were observed to be up-regulated by 15 -fold and 8 -fold, respectively. In addition to the elevated levels of IFN- $\beta$, the 
extract induced the transcription of interferon-stimulatory genes (ISGs), such as ISG-15 and ISG-56 (14-fold and 5-fold), respectively at $8 \mathrm{hpt}$ in RAW264.7 cells. The observed elevated transcriptional patterns for some of the antiviral genes were similar to the pattern of the IFN- $\beta$-treated positive controls. Furthermore, similar transcriptional activation patterns were observed in extract treated HEK293T cells. Interestingly, the highest fold inductions of cellular transcriptional levels were observed at $12 \mathrm{hpt}$ for all the primers. Transcriptional levels of extract-treated HEK293T cells for IFN- $\beta$, GBP-1, IL-6, IL-8, ISG-15, Mx-1 and TNF- $\alpha$ were up-regulated by 8-fold, 5-fold, 30-fold, 2-fold, 5-fold and 2-fold, respectively. Importantly, highest transcriptional induction levels of 90 -fold and 60 -fold were observed for ISG-20 and ISG-56, respectively. All these transcriptional patterns were similar to the pattern of human IFN- $\beta$-treated positive control. The overall results suggest that Epimedium koreanum Nakai has the capacity to up-regulate the transcription levels of IFN- $\beta$, interferon-stimulating genes (ISGs) and various antiviral genes. This molecular-level activation may have a direct relationship with the extract's antiviral abilities, which were observed in both RAW264.7 and HEK293T cells.
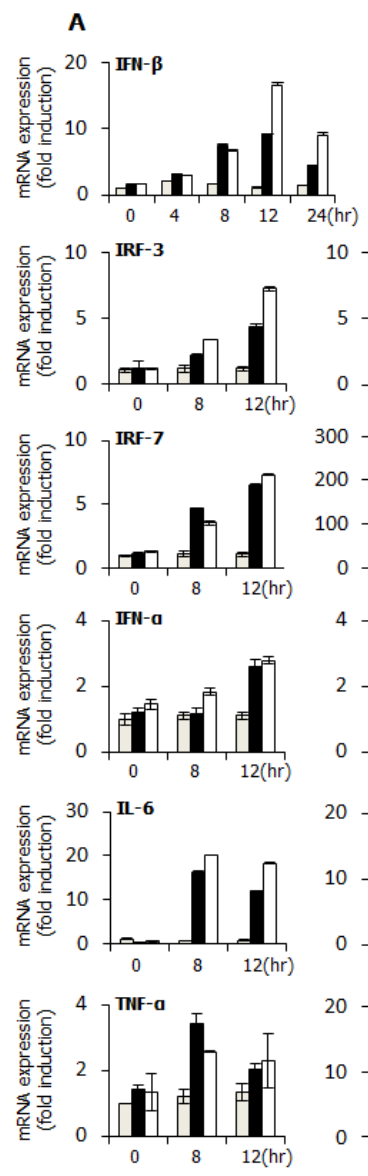
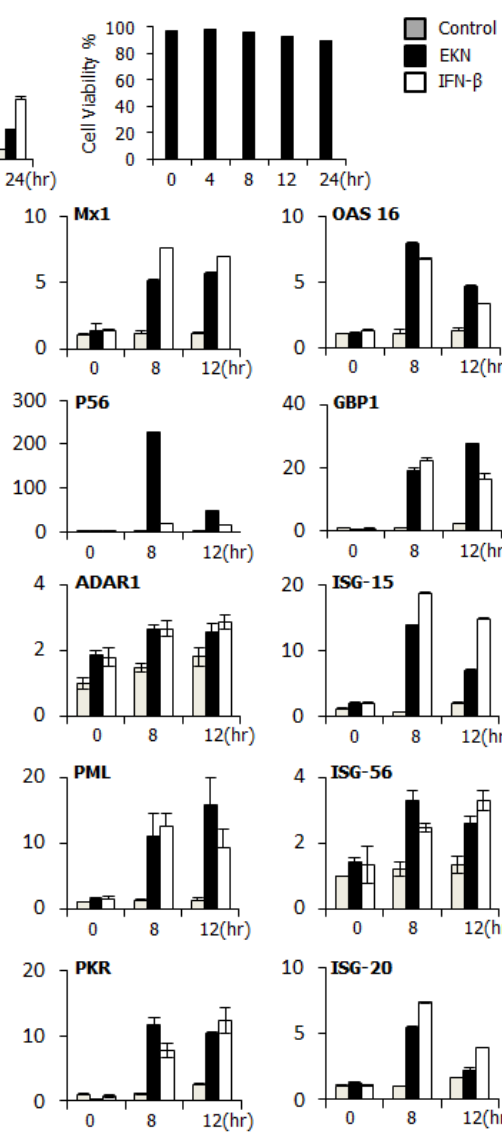

10 OAS 16
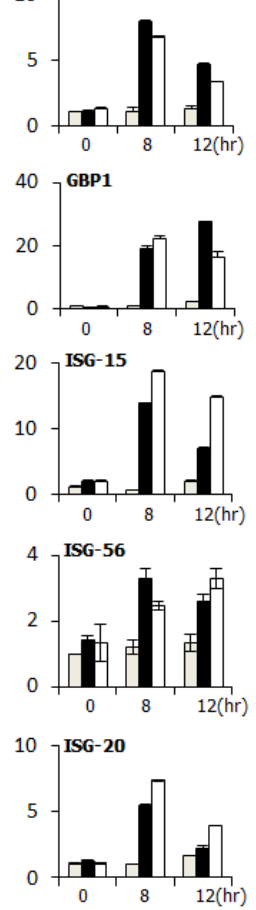

B
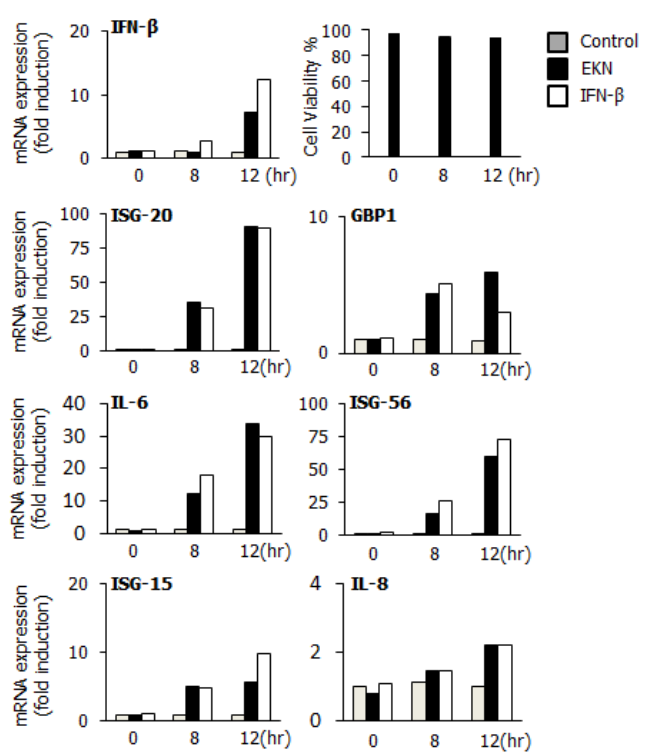

4 ]IL-8
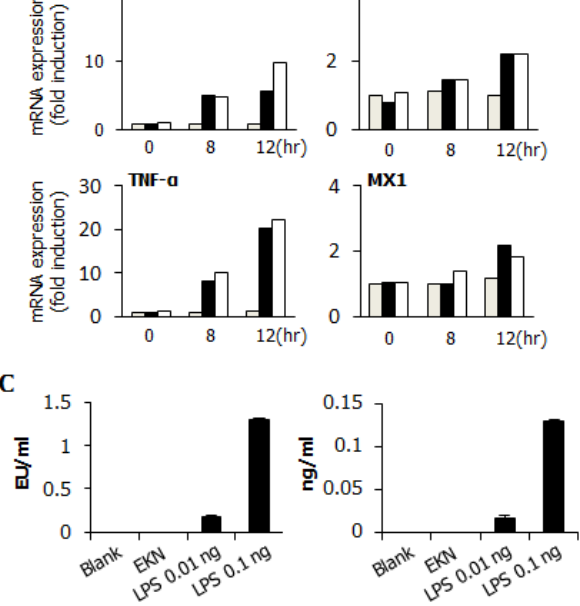

Figure 4. Induction of IFN- $\beta$, IFN-related gene and ISG's transcripts by Epimedium koreanum Nakai in vitro. RAW264.7 and HEK293T cells were treated with DMEM + 10\% FBS alone, Epimedium koreanum Nakai (EKN) $(1.0 \mu \mathrm{g} / \mathrm{mL})$, or 1000 units $/ \mathrm{mL}$ of recombinant murine or human IFN- $\beta$. The time-dependent changes in mRNA expression after treatment in (A) RAW264.7; and (B) HEK293T cells were confirmed by real-time PCR using the primers shown in Tables 2 and 3. Real-time PCR was carried out with the use of a QuantiTect SYBR Green PCR kit (Qiagen) on a Mygenie96 thermal block (Bioneer). Error bars indicate the 
range of values obtained from two independent experiments. (C) Epimedium koreanum Nakai was tested for residual endotoxin contamination using a limulus amebocyte lysate (LAL) assay and was found to not be contaminated with endotoxin. (Cell viabilities were determined by trypan blue exclusion and are expressed as mean $\pm \mathrm{SD}$ ).

Table 2. Mouse primer sets used to confirm mRNA expression.

\begin{tabular}{|c|c|c|}
\hline \multirow{2}{*}{ Gene } & \multicolumn{2}{|c|}{ Primers } \\
\hline & Forward & Reverse \\
\hline IFN- $\beta$ & 5'-TCCAAGAAAGGACGAACATTCG-3' & 5'-TGCGGACATCTCCCACGTCAA-3' \\
\hline Mx1 & 5'-ACAAGCACAGGAAACCGTATCAG-3' & 5'-AGGCAGTTTGGACCATCTTAGTG-3' \\
\hline IRF-3 & 5'-GTGCCTCTCCTGACACCAAT-3' & 5'-CCAAGATCAGGCCATCAAAT-3' \\
\hline IRF-7 & 5'-AAGCTGGAGCCATGGGTATG-3' & 5'-GACCCAGGTCCATGAGGAAG-3' \\
\hline P-56 & 5'-CCCACGCTATACCATCTACC-3' & 5'-CTGAGGCTGCTGCTATCC-3' \\
\hline GBP-1 & 5'-AAAAACTTCGGGGACAGCTT-3' & 5'-CTGAGTCACCTCATAAGCCAAA-3' \\
\hline PML & 5'-CCTGCGCTGACTGACATCTACT-3' & 5'-TGCAACACAGAGGCTGGC-3' \\
\hline ADAR-1 & 5'-CCAAAGACACTTCСТCTC-3' & 5'-CAGTGTGGTGGTTGTACT-3' \\
\hline PKR & 5'-GCCAGATGCACGGAGTAGCC-3' & 5'-GAAAACTTGGCCAAATCCACC-3' \\
\hline OAS-16 & 5'-GAGGCGGTTGGCTGAAGAGG-3' & 5'-GAGGAAGGCTGGCTGTGATTGG-3' \\
\hline ISG-15 & 5'-CAATGGCCTGGGACCTAAA-3' & 5'-CTTCTTCAGTTCTGACACCGTCAT-3' \\
\hline ISG-20 & 5'-AGAGATCACGGACTACAGAA-3' & 5'-TCTGTGGACGTGTCATAGAT-3' \\
\hline ISG-56 & 5'-AGAGAACAGCTACCACCTTT-3' & 5'-TGGACCTGCTCTGAGATTCT-3' \\
\hline IFN-a & 5'-ATAACCTCAGGAACAACAG-3' & 5'-TCATTGCAGAATGAGTCTAGGAG-3' \\
\hline TNF- $\alpha$ & 5'-AGCAAACCACCAAGTGGAGGA-3' & 5'-GCTGGCACCACTAGTTGGTTGT-3' \\
\hline IL-6 & 5'-TCCATCCAGTTGCCTTCTTGG-3' & 5'-CCACGATTTCCCAGAGAACATG-3' \\
\hline GAPDH & 5'-TGACCACAGTCCATGCCATC-3' & 5'-GACGGACACATTGGGGGTAG-3' \\
\hline
\end{tabular}

Table 3. Human primer sets used to confirm mRNA expression.

\begin{tabular}{|c|c|c|}
\hline \multirow{2}{*}{ Gene } & \multicolumn{2}{|c|}{ Primers } \\
\hline & Forward & Reverse \\
\hline IFN- $\beta$ & 5'-CATCAACTATAAGCAGCTCCA-3' & 5'-TTCAAGTGGAGAGCAGTTGAG-3' \\
\hline MX-1 & 5'-CCAAAGACACTTCCTCTC-3' & 5'-CAGTGTGGTGGTTGTACT-3' \\
\hline GBP-1 & 5'-AGAGATCACGGACTACAGAA-3' & 5'-TCTGTGGACGTGTCATAGAT-3' \\
\hline ISG-15 & 5'- GAG AGG CAG CGA ACT CAT CT -3' & 5'- CTT CAG CTC TGA CAC CGA CA -3' \\
\hline ISG-20 & 5'-CTCCTGCACAAGAGCATCCA-3' & 5'-CGTTGCCCTCGCATCTTC-3' \\
\hline ISG-56 & 5'-AAGGCAGGCTGTCCGCTTA-3' & 5'-TCCTGTCCTTCATCCTGAAGCT-3' \\
\hline IL-8 & 5'-CTCTCTTGGCAGCCTTCCTGATT-3' & 5'-АACTTCTCCACAACССТCTGCAC-3' \\
\hline IL-6 & 5'-CCACACAGACAGCCACTCACC-3' & 5'-CTACATTTGCCGAAGAGCCCTC-3' \\
\hline TNF- $\alpha$ & 5' -ATGAGCACTGAAAGCAT-3' & 5'-TCGACGGGGAGTCGAACT-3' \\
\hline$\beta$-actin & 5'-CCAACCGCGAGAAGATGACC-3' & 5'-GATCTTCATGAGGTAGTCAGT-3' \\
\hline
\end{tabular}




\subsection{Protection Against Diverse Influenza A Virus Infection by Oral Administration of Epimedium} koreanum Nakai in Balb/c Mice

To confirm the prophylactic effects of Epimedium koreanum Nakai against diverse influenza A viral infection, after oral inoculation of extracts, groups of BALB/c mice were infected with 5 times of $50 \%$ mouse lethal dose $\left(\mathrm{MLD}_{50}\right)$ of the A/PR/8/34(H1N1), A/Aquaticbird/Korea/W81/2005(H5N2), A/Aquatic bird/Korea/W44/2005(H7N3) or A/Chicken/Korea/116/2004(H9N2) influenza A subtypes. The mice were orally treated with Epimedium koreanum Nakai at $20 \mu \mathrm{g}$ per head in a total volume of $200 \mu \mathrm{L}$ before infection with lethal doses of influenza A subtypes. A minimum effective dose of $20 \mu \mathrm{g}$ per head was chosen based on our previous in vivo experimental experiences with various herbal extracts (data not shown). After the challenge, the untreated (PBS) groups were observed to have severe illnesses and the body weights were found to decrease progressively. Moreover, the control group succumbed to death by 9 days post infection (dpi), regardless of the virus used for the infection. In contrast, the Epimedium koreanum Nakai-treated mice showed a $\leq 20 \%$ body weight loss between 5 and 7 dpi and had begun to recover their lost weight by 8 dpi, returning to their normal state by 13 dpi (Figure 5). Furthermore, all the groups that were orally inoculated with the herbal extract pre-infection had similar protection levels: $80 \%$ for all of the influenza A subtypes tested (Figure 5).
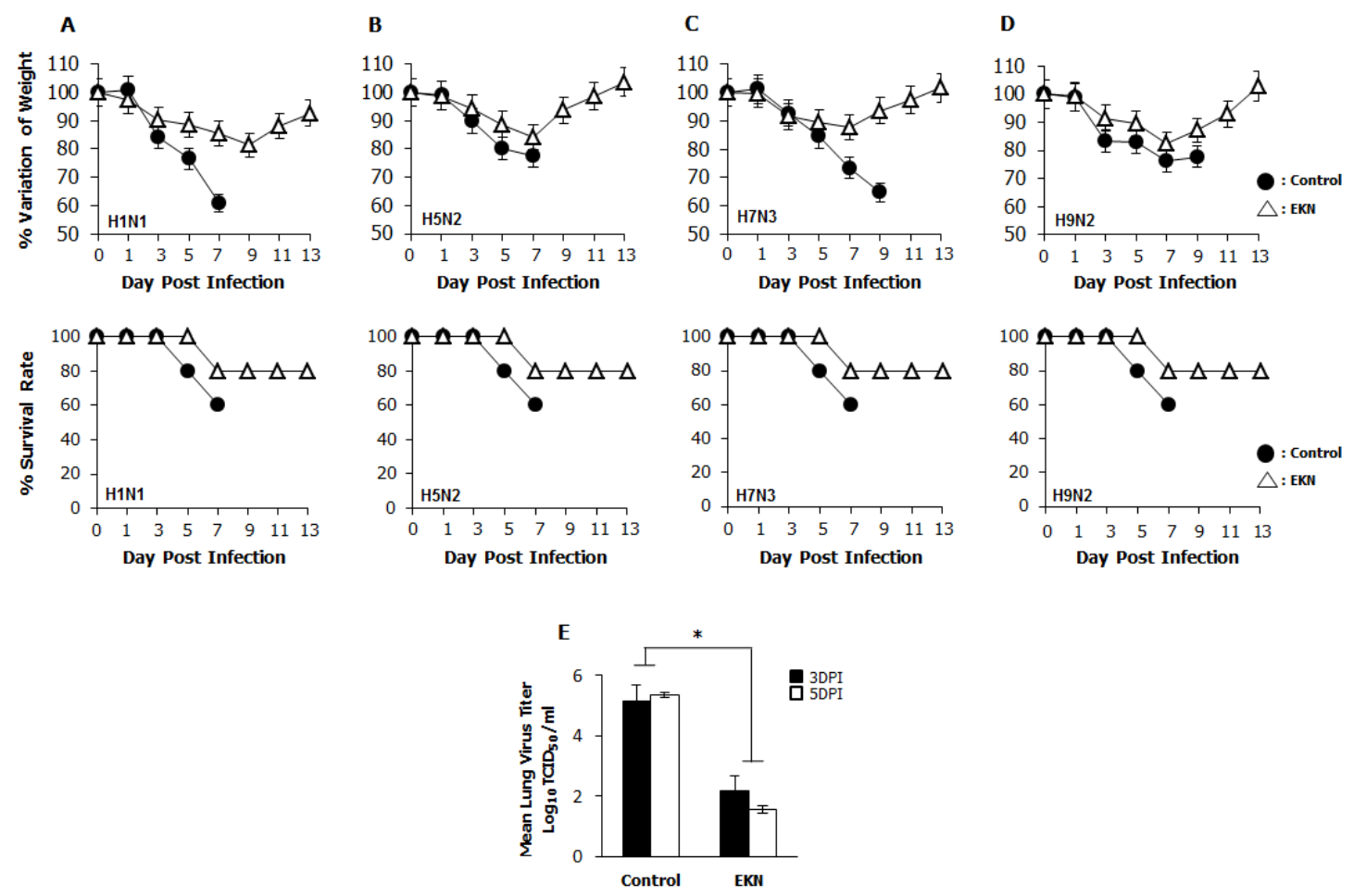

Figure 5. Oral administration of Epimedium koreanum Nakai provides protection against lethal infection with divergent influenza A subtype in BALB/c mice. 5-week-old female $\mathrm{BALB} / \mathrm{c}$ mice were orally administered with $0.1 \mathrm{mg} / \mathrm{mL}$ Epimedium koreanum Nakai (EKN) in a total volume of $200 \mu \mathrm{L}(20 \mu \mathrm{g} / \mathrm{head})$ at 1,3 and 5 days before infection with $5 \mathrm{MLD}_{50}$ (A) H1N1; (B) H5N2; (C) H7N3; and (D) H9N2 Influenza A sub types. Control groups were orally administered with $200 \mu \mathrm{L}$ of PBS. Percentage variation of weight, and percentage survival after challenge were recorded until 13 dpi. (E) Virus titers in lung tissues of the 
H1N1 infected mice were measured by TCID50 at 3 and 5 dpi. ( $* p<0.05$ indicates a significant difference between groups compared by Student's $t$-test).

The ability of Epimedium koreanum Nakai to inhibit viral replication in the lung tissues of infected mice was evaluated in an H1N1-infected experimental set. Three mice from each group were sacrificed, and their lungs were collected 3 and 5 days post-infection for viral titration. Overall, the oral inoculation of Epimedium koreanum Nakai reduced the viral titers in the lungs of the infected mice in the extract-treated groups compared with the untreated controls, which had lung viral titers of $5.13 \log$ TCID $50 / \mathrm{mL}$ and $5.35 \log$ TCID $50 / \mathrm{mL}$ on $3 \mathrm{dpi}$ and $5 \mathrm{dpi}$, respectively. Interestingly, the extract-treated groups had significantly reduced viral titers $2.1 \log$ TCID $50 / \mathrm{mL}$ and $1.5 \log$ TCID $50 / \mathrm{mL}$, at 3 dpi and 5 dpi, respectively (Figure 5E).

Taken together, these results indicate that Epimedium koreanum Nakai induced the antiviral state, which is sufficiently strong to inhibit viral replication and promoted the survival of mice against lethal infections of diverse influenza A viruses.

\subsection{Inhibitory Effect of Quercetin on Influenza Virus (PR8-GFP) and Induction of IFN- $\beta$ or} Pro-Inflammatory Cytokines in RAW264.7 Cells

Epimedium koreanum Nakai is a natural product and contains many effective components. For a detailed understanding of the main component profile of the water extract of Epimedium koreanum Nakai, a high-performance liquid chromatography (HPLC) system was employed. Among marker compounds of Epimedium koreanum Nakai, quercetin and icariin have been representatively identified at $270 \mathrm{~nm}$ based on comparison to the standard compounds (14). Based on this, we tested the anti-influenza (PR8-GFP) effect of quercetin upon pre-treatment of the compound $(5.0 \mu \mathrm{g} / \mathrm{mL})$. Minimum effective dose of $5.0 \mu \mathrm{g} / \mathrm{mL}$ was chosen based on our preliminary experiments on the efficacy of quercetin (data not shown). Interestingly, treatment with quercetin markedly inhibited virus replication (Figure 6A). The quercetin-treated group displayed reduced GFP expression compared to untreated groups, which had high levels of GFP expression. The observed GFP data correlated with the viral titers where, quercetin treatment reduced the viral titers by nearly 3.5 -fold against PR8-GFP at 24 hpi (Figure 6B). Furthermore, treatment of quercetin $(5.0 \mu \mathrm{g} / \mathrm{mL})$ had marked increase in cytokine secretion in RAW264.7 cells (Figure $6 \mathrm{~B})$. These data strongly suggest that quercetin, a major constituent of Epimedium koreanum Nakai, might be able to induce the antiviral state in cells and subsequent inhibition of virus replication.

A

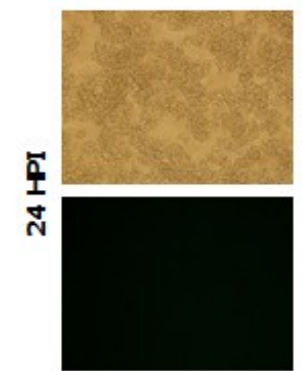

Medium

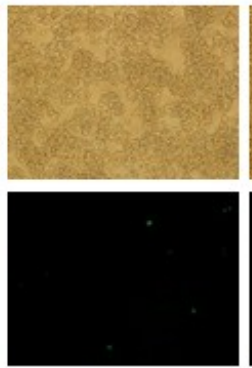

IFN- $\beta$ / PR8-GFP

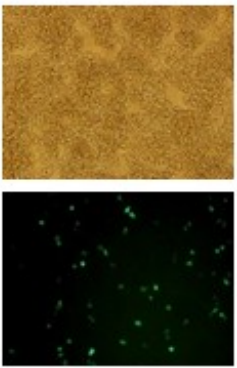

PR8-GFP

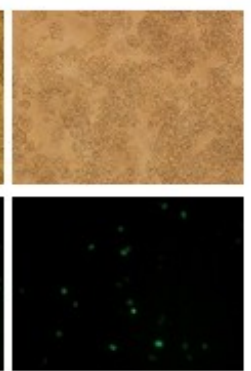

Quercetin /PR8-GFP

Figure 6. Cont. 
B

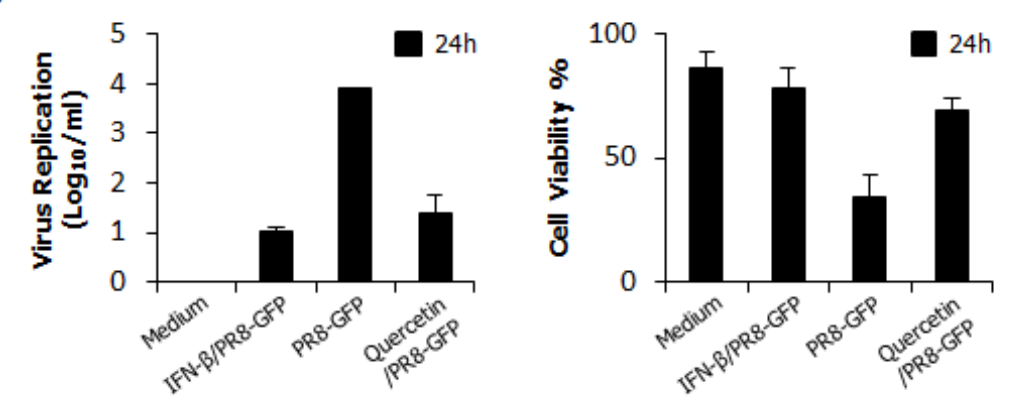

C
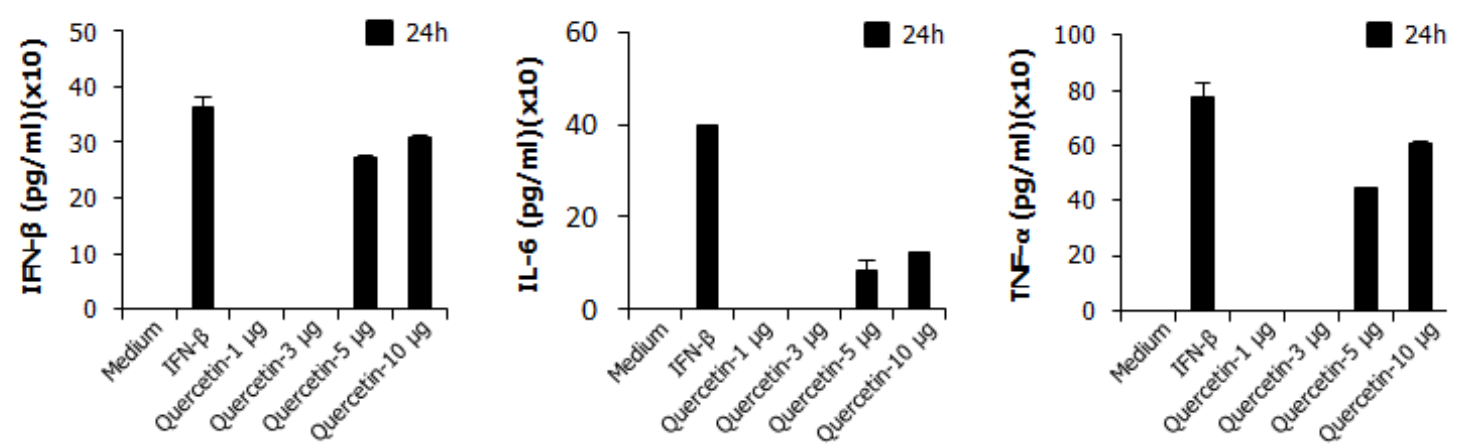

Figure 6. Anti-influenza (PR8-GFP) effect of Quercetin and induction of IFN- $\beta$ and pro-inflammatory cytokines in RAW264.7 cells. (A) RAW264.7 cells treated with media alone, $5.0 \mu \mathrm{g} / \mathrm{mL}$ Quercetin, or $1000 \mathrm{unit} / \mathrm{mL}$ recombinant mouse IFN- $\beta, 12 \mathrm{~h}$ prior to infection with PR8-GFP at an MOI of 1.0 The GFP expression images were obtained at 24 hpi (200× magnification); (B). Viruses were titrated from the infected cells for PR8-GFP. Cell viabilities were determined by trypan blue exclusion and are expressed as mean \pm SD. (C). Supernatant from RAW264.7 cells treated with media alone, with varying concentrations of Quercetin or with 1000 unit/mL recombinant mouse IFN- $\beta$ were harvested at $24 \mathrm{hpt}$ and tested for secreted murine IFN- $\beta$, IL- 6 and TNF- $\alpha$ using capture antibody-coated ELISA plates. The test was performed in duplicate for IFN- $\beta$ and triplicate for other cytokines. The data show the representative means \pm SD of each murine cytokine measured over time.

\subsection{Discussion}

Because of concerns related with the side effects, higher costs and lack of efficacy of conventional medicines, the use of natural products as alternatives to conventional treatment in the healing and treatment of various diseases has been increasing in the last few decades [31]. Among natural products, medicinal plants serve as viable alternatives, safer choices, or in some cases, as the only effective treatment. Moreover, the use of plants as medicines dates to the earliest years of man's evolution [31-33], and therefore poses less safety-related concerns. A larger number of these plants and their isolated constituents have shown beneficial preventive and therapeutic effects, including anti-oxidant, anti-inflammatory, anti-cancer, anti-bacterial, and immune-modulatory properties [34-38].

Moreover, as substitutes for chemosynthesis drugs and vaccines, medicinal plants show potential against a wide range of viruses, such as vaccinia, vesicular stomatis virus, and Sendai virus etc. [39-41]. In particular, the anti-influenza virus effects of several herbal extracts have been reported [42-44]. 
Among the promising medicinal plants, Epimedium koreanum Nakai is an herb with a rich historical background and can mainly be found wild in mainland China and Korea [45].

In this study, we demonstrated that Epimedium koreanum Nakai contains broad spectrum antiviral activity in vitro and against divergent subtypes of influenza $A$ virus in BALB/c mice. In the cytotoxicity of antiviral reagents, Epimedium koreanum Nakai has been used for human consumption for a long time, and side effects after a dose have rarely been reported. Importantly, Epimedium koreanum Nakai did not have any significant cytotoxic effect on the tested cell lines. Moreover, the cell cytotoxic concentration ( $\left.\mathrm{CC}_{50}\right)$ of Epimedium koreanum Nakai was several magnitudes higher than the effective concentrations (EC50) and the selection indexes (SI) of Epimedium koreanum Nakai for various viruses indicate the higher safety margin of the extract for therapeutic and/or prophylactic purposes. First, we found that the total aqueous extract of Epimedium koreanum Nakai inhibited the replication of influenza (Figure 1B), VSV (Figures 1A and 2A), NDV (Figure 1C), and HSV (Figures 1D and 2B) viruses in immune cells (RAW264.7) and epithelial cells (HEK293T). Moreover, oral administration of Epimedium koreanum Nakai increased the survival rate of mice subjected to lethal challenges with different influenza A virus subtypes, including H1N1, H5N2, H7N3 and H9N2 (Figure 5). Although Epimedium koreanum Nakai-inoculated mice initially displayed little weight reduction, the majority of them did not lose more than $25 \%$ of their body weight. In contrast, all of the mice in the control groups displayed more than $25 \%$ losses within 9 dpi and were humanely killed. Influenza virus causes a rapid reduction in the body weight of infected mice. Therefore, $25 \%$ body weight loss is considered the humane end point for sacrificing influenza virus-infected mice [46]. These results suggest that Epimedium koreanum Nakai is sufficiently strong to inhibit viral replication and promoted the survival of mice against lethal infections of diverse influenza A viruses.

After viral infection, the host initially recognizes the infection and rapidly evokes the induction of type I interferons and pro-inflammatory cytokines, generating an anti-viral innate immune response [47]. Induction of the antiviral state at an early point of virus infection is critical to control the spread and pathogenesis of viruses [48]. Likewise, we hypothesized that Epimedium koreanum Nakai induces an antiviral state via the induction of type I interferons and pro-inflammatory cytokines and we determined the induction of antiviral, IFN-stimulated genes (ISGs) (Figure 4) and secretion of IFN- $\beta$ and IL-6 (Figure 3) by Epimedium koreanum Nakai in vitro.

In fact, interferon and pro-inflammatory cytokine production can have both beneficial and harmful effects depending on the amount, timing and duration of cytokine release. For instance, during pathogenic influenza virus infection, robust cytokine production (cytokine storm), excessive inflammatory infiltrates, and virus-induced tissue destruction all contribute to morbidity and mortality [49]. However, an induced antiviral state by tight regulation will be a very important defense mechanism against virus infection [50]. Interestingly, upon challenge with viruses, a notable pattern of cytokine regulation and secretion was observed in Epimedium koreanum Nakai-treated cells, correlating with the observations found in the cell viability assay in this study (Figures 1 and 2).

For a detailed understanding of Epimedium koreanum Nakai on the activation of antiviral signaling, we examined the effect of Epimedium koreanum Nakai on the phosphorylation of IRF-3, p65, TBK1, STAT1, ERK and p38 which are key signaling molecules present in the type I IFN and NF- $\kappa$ B signaling pathways. Upon stimulation of the PRRs (Pattern Recognition Receptors) or unknown receptors of the host cell by foreign materials containing pathogens, downstream signal transduction activities, including 
activation of adaptor signal molecules or transcriptional factors, can initiate the induction of type I interferon and pro-inflammatory cytokines to up-regulate the antiviral status of the host cell [51,52]. In this study, we found that Epimedium koreanum Nakai treatment can induce the phosphorylation of IRF-3, STAT1 and TBK1 in a time-dependent manner, providing evidence of the downstream signal transduction in the type I IFN signaling pathway (Figure $3 \mathrm{C}$ ). Additionally, the activation of NF- $\mathrm{B}$ (p65, pERK, p38), which leads to a strong secretion of pro-inflammatory cytokines, could also be observed. This phosphorylation can lead to the rapid production of type I IFNs and various inflammatory cytokines that play a pivotal role in stimulating the antiviral state and subsequent clearance of viruses [53].

Actually, endotoxin (LPS) is a known immunomodulator and is often a contaminant in biological preparations. Thus, one of the principal concerns in the field is that the macrophage-stimulating properties of the herbal extracts may be due to contamination from bacterial endotoxin (LPS or lipid A-associated protein) [54,55]. Therefore, Epimedium koreanum Nakai was tested for endotoxin contamination using a Limulus Amebocyte Lysate (LAL assay) assay and was found to be contaminated with only trace amounts of endotoxin (Figure 4C).

RAW264.7 cells (mouse macrophages) are versatile immune system cells that play indispensable roles in both the innate and adaptive immune responses [56]. They exhibit various immune responses to pathogenic challenge, such as phagocytosis, cytokine secretion, antigen presentation, and adherence [57]. Because of their wide range of functions, macrophages have been extensively studied for their significant role in the immune system, particularly in antiviral response [58]. Moreover, the immune-stimulating effects of different substances have been well established in murine macrophage cells [23,59-61] and previous studies have elucidated the capacity of murine macrophages to achieve the antiviral state upon successful stimulation $[22,62,63]$. Consequently, we decided to use murine macrophages to evaluate the antiviral effect of the water-soluble herbal extract from Epimedium koreanum Nakai against divergent viruses. In contrast, human embryonic kidney (HEK293T) cells are epithelial cells which are less known for their relationship with the immune system. It is known that HEK293T cells have less prominent pattern recognition receptors (PRRs), especially Toll-like receptors (TLRs) [64]. This suggests that for activating the HEK293T cells, an active compound/s must penetrate the cell membrane and activate the receptors present in the cytoplasm. Therefore, it is clear that aqueous extract of Epimedium koreanum Nakai contains the components which can stimulate both the cell surface PRRs and cytoplasmic PRRs. Therefore, Epimedium koreanum Nakai which has the ability to modulate both RAW264.7 and HEK293T cells in a beneficial manner indicates its broad antiviral potential.

It has been reported that Epimedium koreanum Nakai contains various active components, including flavonoids, flavonol glycosides, alkaloids, polysaccharides and microelements [65,66]. Flavonoids of Epimedium koreanum Nakai mainly contain Icariin, Qercetin, Icariside II, Epimedin, Epimedosides, Hyperoside, and Chlorogenic acid. In our previous study, we identified the main component of Epimedium koreanum Nakai as quercetin and icariin using HPLC [14]. Quercetin, the major active component of Epimedium koreanum Nakai, has been shown to inhibit porcine epidemic diarrhea virus [67,68]. Based on this lead, we tested quercetin for its antiviral activity and immune-modulatory properties. Quercetin displayed striking antiviral properties and induced cytokine secretion (Figure 6) confirming its importance to the observed biological properties. Therefore, the observed antiviral effects of Epimedium koreanum Nakai must be due to the presence of quercetin and other active compounds in 
Epimedium koreanum Nakai, and the relationship between mechanisms of antiviral effects and active compounds containing quercetin must be studied further.

In the present study, we noticed that treatment with the total aqueous extract of Epimedium koreanum Nakai displayed a striking anti-viral effect both in vitro, and in in vivo animal models. As the underlying mechanism, valuable components of Epimedium koreanum Nakai including quercetin could induce the secretion of type I IFN and pro-inflammatory cytokines, stimulating an antiviral state in the host cell and can be a promising prophylactic agent to inhibit viral infections through its activation. However, the optimum dosage of Epimedium koreanum Nakai for practical application and the longevity of the effect within the host should be examined to obtain a better protection against viral infections.

\section{Conclusions}

The present study strongly suggests that the total aqueous extract of Epimedium koreanum Nakai has anti-viral effects against VSV-GFP, PR8-GFP, NDV-GFP and HSV-GFP in vitro and against divergent influenza A subtypes, such as $\mathrm{H} 1 \mathrm{~N} 1, \mathrm{H} 5 \mathrm{~N} 2, \mathrm{H} 7 \mathrm{~N} 3$ and $\mathrm{H} 9 \mathrm{~N} 2$, in the in vivo mouse model. Moreover, our study indicates that extracts of Epimedium koreanum Nakai, which contain quercetin and other active components, can induce the secretion of type I IFN and pro-inflammatory cytokines and the subsequent stimulation of the antiviral state in host cells as a possible mechanism. Thus, the use of Epimedium koreanum Nakai as an orally antiviral agent has the potential to be an effective herbal remedy for prophylaxis and therapeutic applications in both humans and livestock.

\section{Acknowledgments}

The authors thank J.U. Jung of the University of Southern California, USA for providing Green Fluorescence Protein (GFP)-tagged PR8, NDV, VSV and HSV viruses, and Y.K. Choi of Chungbuk National University, Cheongju, Republic of Korea for providing the challenge viruses.

This work was supported by a grant (Grant No. K12050) awarded to the Korean Institute of Oriental Medicine by the Ministry of Education, Science and Technology (MEST), Korea and the Ministry for Food, Agriculture, Forestry and Fisheries, Republic of Korea (Grant No. 112013033SB010).

\section{Author Contributions}

Won-Kyung Cho and Prasanna Weeratunga designed and performed all virus infection experiments, analyzed the data; Byeong-Hoon Lee and Jun-Seol Park executed cell biological experiments; Chul-Joong Kim analyzed the data. Jin Yeul Ma and Jong-Soo Lee designed the overall study and wrote the paper.

\section{Conflicts of Interests}

The authors declare no conflicts of interest 


\section{References}

1. McCaughey, C. Influenza: A virus of our times. Ulst. Med. J. 2010, 79, 46-51.

2. Morens, M.D.; Folkers, G.K.; Fauci, A.S. Perspective What Is a Pandemic; National Institute of Allergy and Infectious Diseases: National Institutes of Health, Bethesda, MD, USA, 2009; pp. 1533-1579.

3. Brownlie, J.; Peckham, C.; Waage, J.; Woolhouse, M.; Lyall, C. Foresight. Infectious Diseases: Preparing for the future Threats; Office of Science and Innovation, Department of Trade and Industry: London, UK, 2006. Available online: https://www.gov.uk/government/uploads/system/ uploads/attachmentdata/file/294243/06-760-infectious-diseases-report.pdf (accessed on 17 November 2014).

4. Morens, D.M.; Fauci, A.S. Emerging Infectious Diseases: Threats to Human Health and Global Stability. PLoS Pathog. 2013, 9, e1003467, doi:10.1371/journal.ppat.1003467.

5. Rajasekaran, D.; Palombo, E.A.; Chia, Y.T.; Lim, S.L.D.; Lee, T.C. Identification of Traditional Medicinal Plant Extracts with Novel Anti-Influenza Activity. PLoS One 2013, 8, e79293, doi:10.1371/journal.pone.0079293.

6. Wang, X.; Jia, W.; Zhao, A. Anti-influenza agents from plants and traditional Chinese medicine. Phytother. Res. 2006, 20, 335-341.

7. Uchide, N.; Toyoda, H. Future target molecules for influenza treatment. Mini. Rev. Med. Chem. 2008, 8, 491-495.

8. Grienke, U.; Schmidtke, M.; Kirchmair, J.; Pfarr, K.; Wutzler, P. Antiviral Potential and Molecular Insight into Neuraminidase Inhibiting Diaryl heptanoids from Alpiniakatsumadai. J. Med. Chem. 2009, 53, 778-786.

9. Ison, M.G. Antivirals and resistance: Influenza virus. Curr. Opin. Virol. 2011, 1, 563-573.

10. Elumalai, A.; Eswariah, M.C. Herbalism-A Review. Inter. J. Photother. 2012, 2, 96-105.

11. Cowan, M.M. Plant products as antimicrobial agents. Clin. Microbil. Rev. 1999, 12, 564-582.

12. Chen, Y.; Zhao, Y.Z.; Jia, X.B.; Hu, M. Intestinal Absorption Mechanisms of Prenylated Flavonoids Present in the Heat-Processed Epimedium koreanum Nakai. Pharm. Res. 2008, 25, 2190-2199.

13. Ma, H.; He, X.; Yang, Y.; Li, M.; Hao, D. The genus Epimedium: An ethno pharmacological and photochemical review. J. Ethnopharmacol. 2011, 134, 519-541.

14. Cho, W.K.; Kim, H.; Choi, Y.J.; Yim, N.H.; Ma, J.Y. Epimedium koreanum Nakai Water Extract Exhibits Antiviral Activity against Porcine Epidermic Diarrhea Virus In Vitro and In Vivo. Evid. Based Complement. Altern. Med. 2008, doi:10.1155/2012/985151.

15. Pachaly, P.; Weibarth, C.S.; Sin, K.S. New Prenyl flavonoid Glycosides from Epimedium koreanum. Planta Med. 1990, 56, 277-280.

16. Liu, C.M.; Zhao, X.L.; Liu, Z.Q.; Xing, J.P. Isolation and Extraction of Total Flavonoids from Epimedium Koreanum Nakai by Supercritical Fluid Extraction. Chem. Res. Chin. Univ. 2004, 20, 707-710.

17. Wang, T.; Zhang, J.C.; Chen, Y.; Huang, F.; Yang, M.S. Comparison of anti-oxidative and antitumor activities of six flavonoids from Epimedium koreanum. J. Chin. Mater. Med. 2007, 32, $715-718$. 
18. Zhang, W.; Chen, H.; Wang, Z.; Lan, G.; Zhang, L. Comparative studies on antioxidant activities of extracts and fractions from the leaves and stem of Epimedium koreanum Nakai. Int. J. Food Sci. Technol. 2011, 50, 1122-1129.

19. Ou, X.; Li, W. Effect on enhancing physical strength and anti-stress activity of flavonoids from the Chinese medicinal plant Epimedium koreanum Nakai. Sci. Res. Essays 2010, 5, 883-886.

20. Tohda, C.; Nagata, A. Epimedium koreanum Extract and Its Constituent Icariin Improve Motor Dysfunction in Spinal Cord Injury. Evid. Based Complement. Altern. Med. 2012, doi:10.1155/2012/731208.

21. Strober, W. Trypan blue exclusion test for cell viability. Curr. Protoc. Cytom. 2001, 64, 9.2.1-9.2.26.

22. Moon, H.J.; Lee, J.S.; Choi, Y.K.; Park, J.Y.; Talactac, M.R. Induction of Type I interferon by high-molecular poly-gamma-glutamate protects B6. A2G-Mx1 mice against influenza A virus. Antivir. Res. 2012, 94, 98-102.

23. Shin, S.M.; Kwon, J.H.; Lee, S.; Kong, H.S.; Lee, S.J.; Lee, C.K.; Cho, K.H.; Ha, N.J.; Kim, K.J. Immunostimulatory effects of Cordyceps militaris on macrophages through enhanced production of cytokines via the activation of NF-KB. Immune Netw. 2010, 10, 55-63.

24. Seal, B.S.; King, D.J.; Bennett, J.D. Characterization of Newcastle Disease Virus Isolates by Reverse Transcription PCR Coupled to Direct Nucleotide Sequencing and Development of Sequence Database for Pathotype Prediction and Molecular Epidemiological Analysis. J. Clin. Microbiol. 1995, 33, 2624-2630.

25. Coil, D.A.; Miller, A.D. Phosphatidylserine is not the cell surface receptor for Vesicular Stomatitis Virus. J. Virol. 2004, 78, 10920-10926.

26. Wadsworth, T.L.; Koop, D.R. Effects of the wine polyphenol icsquercetin and resveratrol on pro-inflammatory cytokine expression in RAW 264.7 macrophages. Inflamm. Immunopharmacol. 1999, 8, 941-949.

27. Quan, F.S.; Compans, R.W.; Huang, C.; Kang, S.M. Virus Like ParticleVaccine Induces Protective Immunity against Homologous and Heterologous Strains of Influenza Virus. J. Virol. 2007, 81, 3514-3524.

28. Zhao, G.; Lin, Y.; Du, L.; Guan, J.; Sun, S.; Sui, H.; Kou, Z.; Chan, C.C.; Guo, Y;, Jiang, S.; Zheng, B.J.; Zhou, Y. . An M2e-based multiple antigenic peptide vaccine protects mice from lethal challenge with divergent H5N1 influenza viruses. Virol. J. 2010, 7, 2-8.

29. Magadula, J.J.; Suleimania, H.O. Cytotoxic and anti-HIV activities of some Tanzanian Garcinia species. Tanzan. J. Health Res. 2010, 12, 24-28.

30. Lin, Xu.; Su, W.; Jin, J.; Chen, J.; Li, X.; Zhang, X.; Sun, M.; Sun, S.; Fan, P.; An, D.; et al. Identification of Luteolin as Enterovirus 71 and Coxsackievirus A16 Inhibitors through Reporter viruses and Cell Viability-Based Screening. Viruses 2014, 6, 2778-2795, doi:10.3390/v6072778.

31. Pan, S.Y.; Zhou, S.F.; Gao, S.H.; Yu, Z.L.; Ko, K.M. New Perspectives on How to Discover Drugs from Herbal Medicines: CAM's Outstanding Contribution to Modern Therapeutics. Evid. Based Complement. Altern. Med. 2013, doi:10.1155/2013/627375.

32. Fong, H.H. Integration of Herbal medicines in to modern medical practices: Issues and prospects. Integr. Cancer Ther. 2002, 1, 287-293.

33. Dattner, A.M. From medical herbalism to phytotherapy in dermatology: Back to the future. Dermatol. Ther. 2008, 16, 106-113. 
34. Thatte, U.M.; Rege, N.N.; Phatak, S.D.; Dahanukar, S.A. The flip side of Ayurveda. J. Postgrad. Med. 1993, 39, 179-182.

35. Salem, M.L.; Hossain, M.S. Protective effect of black seed oil from Nigella sativa against murine cytomegalovirus infection. Int. J. Immunopharmacol. 2000, 22, 729-740.

36. Parab, S.; Kulkarni, R.; Thatte, U. Heavy metals in herbal T medicines. Indian J. Gastroenterol. 2003, 22, 111-112.

37. Huffman, M.A. Animal self-medication and ethno-medicine: Exploration and exploitation of the medicinal properties of plants. Proc. Nutr. Soc. 2003, 62, 371-381.

38. Miller, K.L.; Liebowitz, R.S.; Newby, L.K. Complementary and alternative medicine in cardiovascular disease: A review of biologically based approaches. Am. Heart J. 2004, 147, 401-411.

39. Utsunomiya, T.; Kobayashi, M.; Pollard, R.B.; Suzuki, F. Glycyrrhizin an Active Component of Licorice Roots, Reduces Morbidity and Mortality of Mice Infected with Lethal Doses of Influenza Virus. Antimicrob. Agents Chemother. 1997, 41, 551-556.

40. Pleschka, S.; Stein, M.; Schoop, R.; Hudson, J.B. Anti-viral properties and mode of action of standardized Echinacea purpurea extract against highly pathogenic avian Influenza virus (H5N1, H7N7) and swine-origin H1N1 (S-OIV). Virol. J. 2009, 6, 197-203.

41. Ge, U.; Wang, Y.F.; Xu, J.; Gu, Q.; Liu, H.B.; Xiao, P.G.; Zhou, J.; Liu, Y.; Yang, Z.; Su, H. Anti-influenza agents from Traditional Chinese Medicine. Nat. Prod. Rep. 2010, 27, 1758-1780.

42. He, W.; Han, H.; Wang, W.; Gao, B. Anti-influenza virus effect of aqueous extracts from dandelion. Virol. J. 2011, 8, 538-544.

43. Haruyama, T.; Nagata, K. Anti-influenza virus activity of Ginkgo biloba leaf extracts. J. Nat. Med. 2013, 67, 636-642.

44. Makau, J.N.; Watanabe, K.; Kobayashi, N. Anti-influenza activity of Alchemilla mollis extract: Possible virucidal activity against influenza virus particles. Drug Discov. Ther. 2013, 7, 189-195.

45. Makarovaa, M.N.; Pozharitskayaa, O.N.; Shikova, A.N.; Tesakovaa, S.V.; Tikhonov, V.P. Effect of lipid-based suspension of Epimedium koreanum Nakai extract on sexual behavior in rats. J. Ethnopharmacol. 2007, 114, 412-416.

46. Manicassamy, B.; Medina, R.A.; Hai, R.; Tsibane, T.; Stertz, S. Protection of Mice against Lethal Challenge with 2009 H1N1 Influenza A Virus by 1918-Like and Classical Swine H1N1 Based Vaccines. PLoS Pathog. 2010, 6, e1000745. doi:10.1371/journal.ppat.1000745.

47. Takeuchi, O.; Akira, S. Recognition of viruses by innate immunity. Immunol. Rev. 2007, 220, 214-224.

48. Konopka, J.L.; Thompson, J.M.; Whitmore, A.C.; Webb, D.L.; Johnston, R.E. Acute Infection with Venezuelan Equine Encephalitis Virus Replicon Particles Catalyzes a Systemic Antiviral State and Protects from Lethal Virus Challenge. J. Virol. 2009, 83, 12432-12442, doi:10.1128/JVI.00564-09J.

49. Teijaro, J.R.; Walsh, K.B.; Rice, S.; Rosen, H.; Oldstone, M.B. Mapping the innate signaling cascade essential for cytokine storm during influenza virus infection. Proc. Natl. Acad. Sci. USA 2014, 111, 3799-3804.

50. Goodbourn, S.; Didcock, L.; Randall, R.E. Interferons: Cell signalling, immune modulation, antiviral response and virus countermeasures. J. Gen. Virol. 2000, 81, 2341-2364. 
51. Perry, A.K.; Chow, E.K.; Cheng, G. Differential Requirement for TANK-binding Kinase-1 in Type I Interferon Responses to Toll-like Receptor Activation and Viral Infection. J. Exp. Med. 2004, 199, 1651-1658.

52. Tenoever, B.R.; Ng, S.L.; Chua, M.A.; McWhirter, S.M.; Garcia-Sastre, A.; Maniatis, T. Multiple functions of the IKK-related kinase IKK-epsilon in interferon-mediated antiviral immunity. Science 2007, 315, 1274-1278.

53. Boasso, A. Type I Interferon at the Interface of Antiviral Immunity and Immune Regulation: The Curious Case of HIV-1. Scientifica 2013, doi:10.1155/2013/580968.

54. Schepetkin, I.A.; Quinn, M.T. Botanical polysaccharides: Macrophage immunomodulation and therapeutic potential. Int. Immunopharmacol. 2006, 6, 317-333.

55. Magalhães, P.O.; Lopes, A.M.; Mazzola, P.G.; Rangel-Yagui, C.; Penna, T.C. Methods of endotoxin removal from biological preparations: A review. J. Pharm. Sci. 2007, 10, 388-404.

56. Maurya, M.R.; Gupta, S.; Li, X.; Fahy, E.; Dinasarapu, A.R.; Sud, M.; Brown, H.A; Glass, C.K.; Murphy, R.C.; Russell, D.W.; et al. Analysis of inflammatory and lipid metabolic networks across RAW264.7 and thioglycolate-elicited macrophages. J. Lipid Res. 2013, 54, 2525-2542, doi:10.1194/jlr.M040 212.

57. Karavitis, J.; Kovacs, E.J. Macrophage phagocytosis: Effects of environmental pollutants, alcohol, cigarette smoke, and other external factors. J. Leukoc. Biol. 2011, 90, 1065-1078, doi:10.1189/jlb.0311114.

58. Woods, J.A.; Lu, Q.; Lowder, T. Exercise-induced modulation of macrophage function. Immunol. Cell Biol. 2000, 78, 545-553, doi:10.1111/j.1440-1711.2000.t0109-.x.

59. Wang, J.; Yuan, Y.; Yue, T. Immunostimulatory activities of -d-glucan from Ganoderma lucidum. Carbohydr. Polym. 2014, 102, 47-54.

60. Kim, T.H.; Lee, S.J.; Rim, H.K.; Shin, J.S.; Jung, J.Y.; Heo, J.S.; Kim, J.B.; Lee, M.S.; Lee, K.T. In vitro and in vivo immunostimulatory effects of hot water extracts from the leaves of Artemisia princeps Pampanini cv. Sajabal. J. Ethnopharmacol. 2013, 149, 254-262.

61. Juárez-Vázquez, M.C.; Alonso-Castro, A.J.; García-Carrancá, A. Kaempferitrin induces immunostimulatory effects in vitro. J. Ethnopharmacol. 2013, 148, 337-340.

62. Wilden, H.; Schirrmacher, V.; Fournier, P. Important role of interferon regulatory factor (IRF)-3 in the interferon response of mouse macrophages upon infection by Newcastle disease virus. Int. J. Oncol. 2011, 39, 493-504.

63. Wilden, H.; Fournier, P.; Zawatzky, L.; Schirrmacher, V. Expression of RIG-I, IRF-3, IFN-B and IRF-7 determines resistance or susceptibility of cells to infection by Newcatle Disease Virus. Int. J. Oncol. 2009, 34, 971-982.

64. Graham, K.L.; Lee, L.Y.; Higgins, J.P.; Steinman, L.; Utz, P.J.; Ho, P.P. Treatment with a Toll-like receptor inhibitory GpG oligonucleotide delays and attenuates lupus nephritis in NZB/W mice. Autoimmunity 2014, 43, 140-155, doi:10.3109/08916930903229239.

65. Wu, C.; Sheng, Y.; Zhang, Y.; Zhang, J.; Guo, B. Identification and characterization of active compoundsand their metabolites by high-performance liquidchromatography/Fourier transform ion cyclotronresonance mass spectrometry after oral administration of a herbal extract of Epimedium koreanum Nakai to rats. Rapid. Commun. Mass. Spectrom. 2008, 22, 2813-2824. 
66. Zhang, D.W.; Cheng, Y.; Wang, N.L.; Zhang, J.C.; Yang, M.S. Effects of total flavonoids and flavonol glycosides from Epimedium koreanum Nakai on the proliferation and differentiation of primary osteoblasts. Phytomedicine 2008, 15, 55-61.

67. Choi, H.J.; Kima, J.H.; Lee, C.H.; Ahn, Y.J.; Song, J.H.; Baek. S.H.; Kwona, D.H. Antiviral activity of quercetin 7-rhamnoside against porcine epidemic diarrhea virus. Antivir. Res. 2009, 81, 77-81.

68. Song, J.H.; Shim, J.K.; Choi, H.J. Quercetin 7-rhamnoside reduces porcine epidemic species. Virol. J. 2011, 4, 460-465.

(C) 2015 by the authors; licensee MDPI, Basel, Switzerland. This article is an open access article distributed under the terms and conditions of the Creative Commons Attribution license (http://creativecommons.org/licenses/by/4.0/). 